\title{
Competitive risk sharing contracts with one-sided commitment ${ }^{\hbar}$
}

\author{
Dirk Krueger ${ }^{\mathrm{a}, *}$, Harald Uhlig ${ }^{\mathrm{b}}$ \\ ${ }^{a}$ Department of Business and Economics, Johann Wolfgang Goethe-University Frankfurt am Main, \\ Mertonstr. 17, PF 81, 60054 Frankfurt am Main, Germany, CEPR and NBER, Germany \\ ${ }^{\mathrm{b}}$ Humboldt Universität zu Berlin, CentER, Bundesbank and CEPR, Germany
}

Received 21 February 2005; accepted 5 July 2005

Available online 24 May 2006

\begin{abstract}
This paper analyzes dynamic equilibrium risk sharing contracts between profit-maximizing intermediaries and a large pool of ex ante identical agents that face idiosyncratic income uncertainty that makes them heterogeneous ex post. In any given period, after having observed her income, the agent can walk away from the contract, while the intermediary cannot, i.e. there is one-sided commitment. We consider the extreme scenario that the agents face no costs to walking away, and can sign up with any competing intermediary without any reputational losses. We demonstrate that not only autarky, but also partial and full insurance can obtain, depending on the relative patience of agents and financial intermediaries. Insurance can be provided because in an equilibrium contract an up-front payment effectively locks in the agent with an intermediary. We then show that our contract economy is equivalent to a consumption-savings economy with one-period Arrow securities and a short-sale constraint, similar to Bulow and Rogoff [1989. Sovereign debt: is to forgive to forget? American Economic Review 79, 43-50]. From this equivalence and our characterization of dynamic
\end{abstract}

\footnotetext{
${ }^{2}$ We thank Fernando Alvarez, Hugo Hopenhayn, Urban Jermann, Albert Marcet, James Malcomson, Tom Sargent, Klaus Schmidt, Vivian Yue, four anonymous referees and seminar participants at various seminars and conferences for helpful comments. All remaining errors are our own. For Harald Uhlig, this research was supported by the Deutsche Forschungsgemeinschaft through the SFB 649 "Economic Risk" and by the RTN network MAPMU. Dirk Krueger gratefully acknowledges financial support from the NSF under Grant SES0004376 .

${ }^{*}$ Corresponding author. Tel.: + 496979825289 ; fax: +496979828234.

E-mail address: dirk.krueger@wiwi.uni-frankfurt.de (D. Krueger).
} 
contracts it immediately follows that without cost of switching financial intermediaries debt contracts are not sustainable, even though a risk allocation superior to autarky can be achieved.

(C) 2006 Elsevier B.V. All rights reserved.

JEL classification: G22; E21; D11; D91

Keywords: Long-term contracts; Risk sharing; Limited commitment; Competition

\section{Introduction}

This paper analyzes dynamic equilibrium risk sharing contracts between profitmaximizing financial intermediaries (which we also shall call principals) and agents that face idiosyncratic income uncertainty. In any given period, the agent can walk away from the contract and sign with a competing principal, while the principal itself cannot, i.e. there is one-sided commitment.

The paper is motivated by a common feature of a number of long-term relationships between principals and agents such as those between firms and workers, between international lenders and borrowing countries, between car or health insurers and their clients, or between countries and their citizens. They all have in common that the agents have the option to quit the relationship and engage in a relationship with a competing party, whereas the principal is committed (legally or by some other means) to honor the relationship. ${ }^{1}$ We analyze the relationships listed above from the perspective of providing insurance against unfavorable agent-specific income shocks. In this paper, we take the most extreme perspective and study whether and to what degree relationship capital alone, rather than direct costs of quitting, can support risk-sharing arrangements, when the income process is perfectly observable, when there is perfect competition between the intermediaries.

Without the ability of agents to move between competing principals, the existing "endogenous" incomplete markets literature (e.g. see Thomas and Worrall, 1988; Atkeson, 1991; Kehoe and Levine, 1993, 2001; Kocherlakota, 1996; Krueger, 1999; Krueger and Perri, 1999; Alvarez and Jermann, 2000, 2001 or Ligon et al., 2000) has demonstrated that goodwill can be built up and that substantial risk sharing may be achieved. In this literature it is commonly assumed that the outside option to the risk sharing contract of the agent is financial autarky, and the threat of being expelled into autarky sustains the risk sharing arrangement.

The main purpose of this paper is to endogenize the outside option of agents as being determined by the best possible deal that can be obtained from a competing principal. We investigate to what extent the degree of insurance and the dynamics of consumption in the equilibrium contract is affected by endogenizing this outside option. In the endogenous

\footnotetext{
${ }^{1}$ One area of applications in which the assumption of one- or two-sided limited commitment is particularly natural are dynamic employer-worker relationships. Consequently there exists a rich literature that characterizes (optimal) wage contracts between employers and workers. Important examples include Harris and Holmstrom (1982) and Thomas and Worrall (1988) and Beaudry and DiNardo (1991); a comprehensive review of this literature in provided by Malcomson (1999). Our work is related to this literature since our optimal risk-sharing contracts derived below will share some qualitative features with wage contracts studied in this literature, in particular Harris and Holmstrom (1982).
} 
incomplete markets literature cited above it is the threat of exclusion from future consumption insurance that may enforce some risk sharing in equilibrium. Here we assume that no such threat is credible, and the worst thing an agent can expect from defaulting is an offer from a competing principal of an insurance contract. Since there is no "glue" in the relationship between principal and agent, one may conjecture that the resulting allocation ought to be autarkic in that no risk sharing is possible.

The main results of this paper show that this conjecture is, in general, false. Depending on the relative size of the time discount factor of the agent and the time discount factor of the principal (the inverse of which can be interpreted as the gross real interest rate or the return to some storage technology the principal has access to) in equilibrium no, partial or full insurance of the agent is obtained. If principals and agents discount the future at the same rate, the equilibrium dynamic risk sharing contract necessarily entails full consumption insurance for the agent in the long run. For lower interest rates (that is, if the intermediary is somewhat more patient than the agent), partial insurance will result. Only if the intermediary is very patient and thus interest rates are extremely low, the intuitive autarky result obtains. ${ }^{2}$

If some or complete insurance is possible, the equilibrium contract unfolds as follows. The agent with the strongest incentive to leave her current contract with her principal is the agent with high income. A comparatively impatient principal does mind to extract some resources from this agent now against the promise of consumption insurance later on. As the agent ages on the contract, she turns into a liability for the principal: he has received an initial up-front payment, and is now liable to let the agent consume more than the net present value of her future income. At his stage of the contract our assumption of onesided commitment by the principal is absolutely crucial. ${ }^{3}$ The agent, on the other hand, will not want to walk away (even though she could), since she would be worse off at the beginning of any new contract, in which she again is asked to deliver an up-front payment. That is, any contract necessarily involves pre-payment today for insurance in the future. Since this pre-payment is sunk after the contact has been "signed," it provides the necessary glue between intermediaries and agents that enables some insurance to occur.

A secondary contribution of the paper is to demonstrate that our economy with competitive contracts is equivalent to a consumption-savings problem with one-period Arrow securities and state-dependent short-sale constraints, as in Alvarez and Jermann (2000). Without any costs of moving between principals, the associated short-sale constraints in the consumption-savings economy rule out borrowing altogether. This result mirrors Bulow and Rogoff's (1989) no-lending result in the context of a model of sovereign debt. ${ }^{4}$

Our paper extends the recent literature on endogenous incomplete markets with many ex post heterogeneous agents, as developed in Kehoe and Levine (1993), Kocherlakota (1996) and Alvarez and Jermann (2000). Two papers that also discuss how to endogenize the

\footnotetext{
${ }^{2}$ Ray (2002) also contains an informal discussion of long-term relationships between a principal and agent with different discount factors and exogenous outside options.

${ }^{3}$ Even though we do not model the source of the commitment ability of the principal explicitly in this paper, in most of the applications cited above this commitment is derived from the law that prevents, e.g. health insurers to terminate insurance contracts as long as insurees have not violated the terms of the contract.

${ }^{4}$ The pre-payment nature of the optimal contract is also reminiscent of observed features of health insurance or car insurance: such insurance can typically only be obtained (or only be obtained for "reasonable" premia), if the agent is currently healthy or the driving record is currently clean: the insurance continues, if conditions worsen.
} 
outside option in this general class of models are Phelan (1995) and Lustig (2001). ${ }^{5}$ As in this paper, Phelan (1995) considers an environment where agents can leave the current contract and sign up with another principal. Phelan, too, shows that autarky will not result. However, he assumes that agents can only leave the contract at the beginning of the period, without knowledge of their period income, effectively introducing partial commitment via a one-period waiting time for exiting the contract. With this timing assumption Phelan would actually obtain a full insurance result (not only in the long run, but immediately), would he not assume that the principal cannot observe the endowment of the agent. If endowments were observable in his environment, there would be no reason for an agent to exit even a full insurance contract before knowing her endowment. In contrast, in our full information environment, the agent may exit after she learns her endowments and would surely leave if required to make large payments without future compensation, as in a full insurance contract.

Lustig (2001) endogenizes the outside option in an environment akin to Alvarez and Jermann (2000), in which a small number of agents with income risk enter long-term contracts with endogenous borrowing constraints. Lustig's innovation is to introduce a durable good and to assume that agents lose their collateral upon defaulting on long-term contracts. There are no further punishments from defaulting, and agents can immediately trade in financial markets after default. Consequently in his model all trades are fully collateralized. Our assumption of allowing agents to reenter contractual relationships is similar to Lustig's. His work, however, focuses on asset pricing consequences in the presence of aggregate uncertainty, when the number of participating agents is small, while our paper studies the allocational consequences of long-term contracts with the option of recontracting, assuming a large number of agents and no aggregate uncertainty. Second, while a durable asset is a necessary ingredient in his model, the stark implications in our paper derive from its absence. ${ }^{6}$

The structure of the paper is as follows. Section 2 describes the model and defines equilibrium. Section 3 provides the analysis. After proving existence of equilibrium, we argue that, depending on the relationship between the discount factor of agents and the interest rate, either no, full or partial risk sharing is possible. The following subsections then analyze these cases in turn: Section 3.3 provides the upper bound for the interest rate which allows for the autarky result. In Section 3.4 we provide a complete characterization of the contract in the case of iid income and $\beta R=1$, resulting in full risk sharing and constant consumption above average income in the limit. For the iid two-income case, we also provide a complete characterization of the partial insurance equilibrium for $\beta R<1$ in

\footnotetext{
${ }^{5}$ For an example of endogenizing the outside option to long-term relationships by competition in a very different environment, see Ghosh and Ray (1996).

${ }^{6}$ Another literature that studies consumption insurance with long-term contracts derives incomplete risksharing from the presence of private information and moral hazard. In this literature it is usually assumed that both agents and competitive principals can commit to the long-term contract. Competition of principals for agents takes place only at the first period, with no recontracting allowed at future dates. Green (1987) offers a partial equilibrium treatment of such an economy, while Atkeson and Lucas $(1992,1995)$ extend the analysis to general equilibrium, Atkeson (1991) applies such a model to sovereign lending, Phelan (1994) incorporates aggregate shocks and Malcomson and Spinnewyn (1988) study the importance of commitment to long-term contracts in achieving efficient allocations in a dynamic moral hazard environment.

Whether a sequence of short-term contracts is able to attain outcomes as good as long-term contracts under private information is also the central point of investigation in the work of Fudenberg et al. (1990) and Rey and Salanie (1990, 1996).
} 
Section 3.5. Finally, in Section 3.6 we show that there is a general duality between the longterm contracts economy considered in this paper and a consumption-savings problem with state-contingent one-period Arrow securities and borrowing constraints. We also show that one can reinterpret competition with other principals as a requirement that the contract is proof from renegotiation demands by the agent. Section 4 concludes. A sequential formulation of the game between agents and principals can be found in Appendix A. A separate appendix contains details of the longer proofs in the main text. ${ }^{7}$

\section{The model}

\subsection{The environment}

The economy consists of a continuum of principals $j \in[0,1]$, each initially associated with a measure $\mu_{j} \geqslant 0$ of atomless agents. The total population of atomless "agents" is $\sum_{j} \mu_{j}=1$. We denote a generic agent by $i$.

Each individual $i$ has a stochastic endowment process $\left\{y_{t, i}\right\}_{t=0}^{\infty}$ of the single consumption good with finite support $Y=\left\{y_{1}, \ldots y_{m}\right\}, m \geqslant 2$, drawn as Markov process with strictly positive transition probabilities $\pi\left(y^{\prime} \mid y\right)$. We assume that $Y$ is ordered: $y_{j-1}<y_{j}$ for all $j=2, \ldots, m$. Endowment realizations are publicly observable. Let $\Pi$ denote the stationary measure associated with $\pi$, and note that it is unique. Also assume that $\sum_{y} y \Pi(y)=1$ and that the initial distribution over endowments at each principal at date 0 is given by $\Pi$.

Agents value consumption according to the utility function

$$
U\left(\left(c_{t, i}\right)_{t=0}^{\infty}\right)=(1-\beta) E_{0}\left[\sum_{t=0}^{\infty} \beta^{t} u\left(c_{t, i}\right)\right],
$$

where $u: \mathbf{R}_{+} \rightarrow \mathbf{D}$ is the period utility function, with range $\mathbf{D}$, and where $0<\beta<1$. We assume that $u(c)$ is continuously differentiable, strictly concave and strictly increasing in $c$ and satisfies the Inada conditions.

A principal $j$ has no endowment of the consumption good and consumes $\gamma_{t, j}$ in period $t$. The principal is risk neutral and values consumption according to

$$
U^{(P)}\left(\left(\gamma_{t, j}\right)_{t=0}^{\infty}\right)=\left(1-\frac{1}{R}\right) E_{0}\left[\sum_{t=0}^{\infty} \frac{\gamma_{t, j}}{R^{t}}\right],
$$

where $0<(1 / R)<1$ is the discount factor of the principal and an exogenous parameter of the model, which can also be interpreted as the exogenous gross interest rate. Alternatively one could assume that there is an economy-wide storage technology that principals have access to which has a gross return of $R$. We explicitly allow consumption or "cash flow" of the principal, $\gamma_{t, j}$, to be negative. This also avoids ever having to worry about bankruptcy of a principal. ${ }^{8}$

We allow the interest rate $R$ to differ from the reciprocal of the discount factor $\beta$ of the agent. The normalization with the factor $(1-1 / R)$ has the advantage, that a constant $\gamma_{t, j} \equiv \gamma$ results in $U^{(P)}=\gamma$, so that both are expressed in the same units; this simplifies some

\footnotetext{
${ }^{7}$ Available at http://www.wiwi.uni-frankfurt.de/professoren/krueger/harapp.pdf

${ }^{8}$ Alternatively, one may allow principals to go short in the storage technology, although this will never happen in equilibrium, as we will show that equilibrium insurance contracts necessarily entail pre-payment by the agents.
} 
of the expressions below (a similar argument justifies the normalization of the agents' utility function by $(1-\beta))$. One may interpret $U^{(P)}$ as the net present value of a stream of cash flow $\gamma_{t, j}$ discounted at the market return $R$, assuming that goods can be traded across principals, although we do not explore this interpretation further to keep matters simple.

For each principal the resource constraint posits that

$$
Y_{t, j}=C_{t, j}+\gamma_{t, j}
$$

where $Y_{t, j}=\int y_{t, i} \mu_{j}(\mathrm{~d} i)$ is total endowment of agents associated with principal $j$ and $C_{t, j}=$ $\int c_{t, i} \mu_{j}(\mathrm{~d} i)$ is total consumption of these agents.

\subsection{Market structure}

In this economy agents wish to obtain insurance against stochastic endowment fluctuations from risk neutral principals. We want to characterize long-term consumption insurance contracts that competitive profit-maximizing principals offer to agents that cannot commit to honor these contracts. After the realization of income $y_{t, i}$, but before consumption takes place, an agent is free to leave the principal and join a competitor. She takes the current income realization with her. We assume that moving is "painful" to the agent, inflicting a disutility $v\left(y_{t, i}\right) \geqslant 0$. For most of the paper, we will concentrate on the case $v(\cdot) \equiv 0$, that is, moving carries no direct cost. A principal has the ability to commit to long-term contracts with his agents, but has no ability to reach them in the future, once they have left for a competitor. In short, this is an environment with one-sided commitment. $^{9}$

We now formulate a game of competition between principals, offering consumption contracts to potential movers and to agents already with the principal. We proceed directly to the recursive formulation of each individual principal's optimization problem, and then to define a symmetric stationary recursive equilibrium. We thereby skip the step of first describing the game as unfolding sequentially; for completeness, that formulation can be found in Appendix A.

\subsection{Recursive equilibrium}

An agent enters the period with current state $(y, w)$, describing her current income $y$ and the expected discounted utility $w$ from the contract she had been promised by the principal last period. The fact that utility promises $w$ and the current shock $y$ form a sufficient description of an agent's state, in the sense that the resulting policy functions of the recursive problem induce consumption and investment sequences that solve the corresponding sequential optimization problem, has been demonstrated by Atkeson and Lucas (1992) for a private information economy and adapted to the environment presented here by Krueger (1999). Both papers borrow the idea of promised utility as a state variable from Abreu et al. (1986) and Spear and Srivastava (1987).

\footnotetext{
${ }^{9}$ Section 3.6 demonstrates that the same consumption allocation as with long-term contracts arises if agents are allowed to trade one-period state-contingent savings-loan contracts, subject to judiciously specified short-sale constraints. In that section we also discuss the connection between our long-term competitive contracts and renegotiation-proof contracts in a bilateral bargaining game between a single principal and agent.
} 
The objective of the principal is to maximize the contribution to his own lifetime utility (lifetime profit) from the contract with a particular agent. He is constrained to deliver the utility promise $w$ by giving the agent current consumption $c$ and utility promises from next period onwards, contingent on next period's income realization, $w^{\prime}\left(y^{\prime}\right)$. If the principal promises less utility from tomorrow onward in a particular income realization $y^{\prime}$ than a competing principal, the agent will leave the location, and the principal makes zero profits from the contract with that particular agent from then on. ${ }^{10}$ We denote the utility promise by competing principals as $U^{\mathrm{Out}}\left(y^{\prime}\right)$, which the principal takes as given (but which is determined in equilibrium). The recursive problem of a principal can be stated as

$$
\begin{aligned}
& \begin{aligned}
P(y, w)= & \max _{c,\left\{w^{\prime}\left(y^{\prime}\right)\right\} y^{\prime} \in Y}\left(1-\frac{1}{R}\right)(y-c) \\
& +\frac{1}{R} \sum_{y^{\prime} \in Y} \pi\left(y^{\prime} \mid y\right) \begin{cases}P\left(y^{\prime}, w^{\prime}\left(y^{\prime}\right)\right) & \text { if } w^{\prime}\left(y^{\prime}\right) \geqslant U^{\mathrm{Out}}\left(y^{\prime}\right)-v\left(y^{\prime}\right), \\
0 & \text { if } w^{\prime}\left(y^{\prime}\right)<U^{\mathrm{Out}}\left(y^{\prime}\right)-v\left(y^{\prime}\right),\end{cases}
\end{aligned} \\
& \text { s.t. } w=(1-\beta) u(c)+\beta \sum_{y^{\prime} \in Y} \pi\left(y^{\prime} \mid y\right) w^{\prime}\left(y^{\prime}\right),
\end{aligned}
$$

where $v\left(y^{\prime}\right)$ is the "pain" of moving to a competing principal.

The promise keeping constraint (5) says that the principal delivers lifetime utility $w$ to an agent which was promised $w$, either by allocating current or future utility to the agent. This constraint of the principal makes our assumption of one-sided commitment explicit: in contrast to the agents principals are assumed to be able to commit to the long-term relationship. Finally, that continuation profits split into two parts is due to the fact that, in order to retain an agent, the principal has to guarantee her at least as much continuation utility, in any contingency, as the agent would obtain from a competing principal.

Let us now consider what our assumption of competition among principals amounts to. For a principal it only makes sense to attract a new agent if the profit from this new contract is nonnegative. On the other hand, suppose that an agent could be attracted with a contract generating positive profit. Then another principal could make a profit by offering a slightly better contract. Hence, perfect competition between principals implies that the profit from a new contract exactly equals zero and that the utility promised to the newcomer is the highest utility promise achievable subject to this constraint. We require the result of this argument as an equilibrium condition by imposing that $U^{\text {Out }}(y)$ equals the highest lifetime utility $w$ satisfying $P(y, w)=0$.

Given this condition we can simplify the dynamic programming problem above, as the principal is always indifferent between letting an agent go by offering $w^{\prime}\left(y^{\prime}\right)<U^{\text {Out }}\left(y^{\prime}\right)-v\left(y^{\prime}\right)$ or letting him stay by offering him exactly $w^{\prime}\left(y^{\prime}\right)=U^{\text {Out }}\left(y^{\prime}\right)-$ $v\left(y^{\prime}\right)$ and making zero expected profits from tomorrow onwards. We restrict attention to the latter case. ${ }^{11}$ The dynamic programming (4) can then be restated as a cost

\footnotetext{
${ }^{10}$ If the agent is indifferent, we make the tie-breaking assumption that the agent stays with the current principal. Note that an agent always finds it preferable to sign up with a competing intermediary rather than live in financial autarky (even if she could save in a risk-free technology with gross return $R$ ) because a financial intermediary offers contracts that smooth consumption across states and not only across time.

${ }^{11}$ If $v(y)=0$ for all $y$ this restriction is without loss of generality, since an agent starts the next period with promise $U^{\text {Out }}\left(y^{\prime}\right)$, independent of whether she moved or not.
} 
minimization problem

$$
\begin{aligned}
& V(y, w)=\min _{c,\left\{w^{\prime}\left(y^{\prime}\right)\right\}_{y^{\prime} \in Y}}\left(1-\frac{1}{R}\right) c+\frac{1}{R} \sum_{y^{\prime} \in Y} \pi\left(y^{\prime} \mid y\right) V\left(y^{\prime}, w^{\prime}\left(y^{\prime}\right)\right), \\
& \text { s.t. } w=(1-\beta) u(c)+\beta \sum_{y^{\prime} \in Y} \pi\left(y^{\prime} \mid y\right) w^{\prime}\left(y^{\prime}\right), \\
& w^{\prime}\left(y^{\prime}\right) \geqslant U^{\text {Out }}\left(y^{\prime}\right)-v\left(y^{\prime}\right) \quad \text { for all } y^{\prime} \in Y,
\end{aligned}
$$

where (8) now captures the constraints that competition impose on the principal and the argument above that it is never strictly beneficial for a principal to lose an agent to a competing principal.

With this recursive formulation of the principal's problem we can now restate the zeroprofit condition. Let $a(y)$ be the (normalized) present discounted value of the endowment stream discounted at interest rate $R$ and given current endowment $y$. Hence $a(y)$ is defined recursively as

$$
a(y)=\left(1-\frac{1}{R}\right) y+\frac{1}{R} \sum_{y^{\prime}} \pi\left(y^{\prime} \mid y\right) a\left(y^{\prime}\right) .
$$

One can read $a(y)$ as the human wealth of an agent with current income $y$, as evaluated by the principal. Perfect competition implies that the normalized expected net present value of consumption spent on this agent exactly equals her human wealth $a(y)$, i.e.

$$
V\left(y, U^{\text {Out }}(y)\right)=a(y) \quad \text { for all } y \in Y
$$

and that the utility $U^{\text {Out }}(y)$ promised to a newcomer is the highest utility promise achievable subject to the principal breaking even.

In order to define equilibrium we have to precisely fix the domain of admissible utility promises. Let $\mathscr{W}=[\underline{w}, \bar{w}]$ be this domain, with $\underline{w}$ being its lower and $\bar{w}$ its upper bound and let $Z=Y \times[w, \bar{w}]$. For the results to follow it is useful to provide explicit bounds $[\underline{w}, \bar{w}]$. To do so define $\bar{a}=\max _{j} a\left(y_{j}\right)$ and

$$
\begin{aligned}
& \bar{w}=\max _{\left(c_{t}\right)_{t=0}^{\infty}}(1-\beta) \sum_{t=0}^{\infty} \beta^{t} u\left(c_{t}\right), \\
& \text { s.t. }\left(1-\frac{1}{R}\right) \sum_{t=0}^{\infty} \frac{1}{R^{t}} c_{t} \leqslant \bar{a} .
\end{aligned}
$$

That is, $\bar{w}$ is the lifetime utility an agent with highest lifetime income $\bar{a}$ could maximally receive from a principal who does not worry about the agent leaving the contract at some future point and who wishes to avoid a loss. ${ }^{12}$ Furthermore, pick some $0<\underline{y}<y_{1}$ and define $\underline{w}=u(\underline{y})$. Note that $\underline{w}<\min _{j} w_{\text {aut }}\left(y_{j}\right)$ (where $w_{\text {aut }}\left(y_{j}\right)$ is the utility from consuming its income forever, given current income $y_{j}$ ) That is, $\underline{w}$ is the lifetime utility from consuming a

${ }^{12}$ For example, if $u(c)=\left(c^{1-\sigma}-1\right) /(1-\sigma)$, a tedious but simple calculation shows that $\bar{w}=u(\bar{c})$, where

$$
\bar{c}=\frac{1-R^{-1}(\beta R)^{1 / \sigma}}{1-R^{-1}}\left(\frac{1-\beta}{1-\beta(\beta R)^{(1 / \sigma)-1)}}\right)^{1 /(1-\sigma)} \bar{a} \leqslant \bar{a} \quad \text { for } \beta R \leqslant 1,
$$

with the inequality strict for $\beta R<1$ and $\sigma<\infty$. 
constant endowment $y$ smaller than the lowest income realization $y_{1}$. In order to assure that the dynamic programming problem of the principal is always well-defined we impose

Condition 1. The bounds $[\underline{w}, \bar{w}]$ satisfy

$$
\underline{w}>(1-\beta) \inf (\mathbf{D})+\beta \bar{w},
$$

where $\mathbf{D}$ is the range of the period utility function.

Note that this condition, purely in terms of fundamentals of the economy, is always satisfied for utility functions that are unbounded below (e.g. CRRA functions with $\sigma \geqslant 1$ ). For other period utility functions, for $\bar{w}$ as defined above and a given $\underline{w}=u(y)$ there always exists a $\beta \in(0,1)$ low enough such that condition 1 is satisfied. We are now ready to define a symmetric stationary recursive competitive equilibrium.

Definition 2. A symmetric stationary recursive equilibrium is functions $V: Z \rightarrow \mathbf{R}$, $c: Z \rightarrow \mathbf{R}_{+}, w^{\prime}: Z \times Y \rightarrow[\underline{w}, \bar{w}], U^{\text {Out }}: Y \rightarrow[\underline{w}, \bar{w}]$, principal consumption $\gamma \in \mathbf{R}$ and a positive measure $\Phi$ on the Borel sets of $Z$ such that

1. solution of Bellman equation: $V$ solves the functional equation above and $c, w^{\prime}$ are the associated policies, given $U^{\text {Out }}\left(y^{\prime}\right)$ for all $y^{\prime} \in Y$;

2. feasibility:

$$
\gamma+\int(c(y, w)-y) \mathrm{d} \Phi=0
$$

3. outside option: for all $y \in Y$

$$
U^{\text {Out }}(y) \in \arg \max _{w}\{w \mid V(y, w)=a(y)\} ;
$$

4. stationary distribution:

$$
\Phi=H(\Phi),
$$

where $H$ is the law of motion for the measure over $(y, w)$ induced by the income transition matrix $\pi$ and the optimal policy function $w^{\prime}$.

The law of motion $H$ is given as follows. The exogenous Markov chain $\pi$ for income together with the policy function $w^{\prime}$ define a Markov transition function on the measurable space $(Z, \mathscr{B}(Z))$ where $\mathscr{B}(Z)$ denotes the Borel sigma algebra on $Z$. Define the transition function $Q: Z \times \mathscr{B}(Z) \rightarrow[0,1]$ by

$$
Q((y, w), A)=\sum_{y^{\prime} \in Y} \begin{cases}\pi\left(y^{\prime} \mid y\right) & \text { if }\left(y^{\prime}, w^{\prime}\left(y, w ; y^{\prime}\right)\right) \in A, \\ 0 & \text { else, }\end{cases}
$$

for all $A \in \mathscr{B}(Z)$. Then the law of motion is defined as

$$
H(\Phi)(A)=\int Q(z, A) \Phi(\mathrm{d} z) \quad \text { for all } A \in \mathscr{B}(Z) .
$$

Two comments are in order. First, the range for $w$ defined by $[\underline{w}, \bar{w}]$ is meant to precisely fix the domain of the relevant functions rather than act as another restriction. Second, 
agents arrive with a "blank" history at a new principal, i.e. the principal does not make particular use of the information that new arrivals must be agents who have previously defaulted. This assumption rules out cooperation (e.g. via credit rating agencies) by principals in punishing defaulting agents. ${ }^{13}$ While it might be interesting to study an extension allowing for such institutions, the assumption of perfect competition among principals is not different from the usual assumption maintained in Walrasian economies. $^{14}$

\section{Analysis}

The analysis of our model contains several parts. In Section 3.1 we establish basic properties of the principals' dynamic program problem and in Section 3.2 we prove existence of equilibrium. Sections 3.3-3.5 contain characterizations of the equilibrium risk sharing contract under different assumptions about the relative magnitude of the time discount factor of agents, $\beta$, and principal, $1 / R$. Finally, Section 3.6 argues that the consumption allocations characterized in the previous subsection would also arise as a solution to a simple consumption-savings problem or as an outcome of a renegotiationproof bilateral contract between a single principle and agent.

\subsection{Properties of the Bellman equation}

Let us first state properties of solutions to the dynamic programming problem of the principal. Define the cost function $C: \mathbf{D} \rightarrow \mathbf{R}_{+}$as the inverse of the period utility function $u$. That is, $C(u)$ is the consumption needed to deliver current utility $u$. From the properties of the utility function it follows that $C(\cdot)$ is strictly convex, differentiable, strictly increasing, and $\inf _{u \in D} C(u)=0$ and $\sup _{u \in D} C(u)=\infty$. Rather than current consumption $c$ we let the principal choose current utility $h=u(c)$ with associated cost $C(h)$. The Bellman equation then reads as

$$
\begin{aligned}
& V(y, w)=\min _{h \in D,\left\{w^{\prime}\left(y^{\prime}\right) \in[\underline{w}, \bar{w}]\right\}_{y^{\prime} \in Y}}\left(1-\frac{1}{R}\right) C(h)+\frac{1}{R} \sum_{y^{\prime} \in Y} \pi\left(y^{\prime} \mid y\right) V\left(y^{\prime}, w^{\prime}\left(y^{\prime}\right)\right), \\
& \text { s.t. } w=(1-\beta) h+\beta \sum_{y^{\prime} \in Y} \pi\left(y^{\prime} \mid y\right) w^{\prime}\left(y^{\prime}\right)
\end{aligned}
$$

and subject to (8). We define an optimal contract, given outside options, as solution to the dynamic programming problem of the principal, or formally:

\footnotetext{
${ }^{13}$ One justification for this is that it is not in the competing principals' best interest to honor such cooperation ex post.

${ }^{14}$ In the context of the sovereign debt literature Kletzer and Wright (2000) study an economy with one borrower countries and multiple lenders. By allowing lenders to act strategically and punish lenders who offer contracts inducing agents to leave the original lender some sovereign debt can be sustained. Our assumption of perfect competition is meant to rule out such strategic (or alternatively, cooperative) behavior among principals; our analysis thus provides a complement to theirs. Our assumption of perfect competition has the additional appeal that the informational requirements for the principals are substantially lower than with strategic interactions among principals.
} 
Definition 3. Given $[\underline{w}, \bar{w}]$ and $U^{\text {Out }}(y)_{y \in Y}$ in $[\underline{w}, \bar{w}]$, an optimal contract for $\left(\left(U^{\text {Out }}(y)\right)_{y \in Y}, \underline{w}, \bar{w}\right)$ is a solution $V(y, w)$ to the Bellman equation on the domain $Z$ together with associated decision rules $h=h(y, w), w^{\prime}\left(y^{\prime}\right)=w^{\prime}\left(y, w ; y^{\prime}\right)$.

We are now ready to establish basic properties of the optimal contract (dynamic program) of the principal.

Proposition 4. Let outside options $\left(U^{\mathrm{Out}}(y)\right)_{y \in Y} \in[\underline{w}, \bar{w}]$ and $\beta<1<R$ be given. Further suppose that Condition 1 is satisfied. Then, an optimal contract for $\left(\left(U^{\mathrm{Out}}(y)\right)_{y \in Y}, \underline{w}, \bar{w}\right)$ exists and has the following properties.

1. $V(y, w)$ is strictly convex, strictly increasing, continuous and differentiable in $w$.

2. The decision rules are unique and continuous.

3. The decision rules and the value function satisfy the first order conditions and the envelope condition

$$
\begin{aligned}
& (1-\beta) \lambda=\left(1-\frac{1}{R}\right) C^{\prime}(h), \\
& \lambda \beta=\frac{1}{R} \frac{\partial V}{\partial w}\left(y^{\prime}, w^{\prime}\left(y, w ; y^{\prime}\right)\right)-\mu\left(y^{\prime}\right), \\
& \lambda=\frac{\partial V}{\partial w}(y, w), \\
& \lambda \geqslant 0, \\
& \mu\left(y^{\prime}\right) \geqslant 0 \text { for all } y^{\prime} \in Y,
\end{aligned}
$$

where $\lambda$ and $\mu\left(y^{\prime}\right)$ are the Lagrange multipliers on the first and second constraints.

4. The decision rule $h(y, w)$ is strictly increasing in $w$. The decision rule $w^{\prime}\left(y, w ; y^{\prime}\right)$ is weakly increasing in $w$, and strictly so, if the continuing participation constraint $w^{\prime}\left(y, w ; y^{\prime}\right) \geqslant U^{\text {Out }}\left(y^{\prime}\right)-v\left(y^{\prime}\right)$ is not binding.

5. If the income process is iid, then $V(y, w)$ depends on $w$ alone, $V(y, w) \equiv V(w)$. If additionally $U^{\text {Out }}\left(y^{\prime}\right)-v\left(y^{\prime}\right)$ is weakly increasing in $y^{\prime}$, then $w^{\prime}\left(y, w ; y^{\prime}\right)$ is weakly increasing in $y^{\prime}$.

Proof. All arguments are similar to those in Krueger (1999) and fairly standard, apart possibly from the strict convexity of the value function. We will give a sketch of the argument here and defer details to the technical appendix.

1. Assumption 1 assures that the constraint set is nonempty. A standard contraction mapping argument then assures existence, strict monotonicity and convexity of $V$. Strict convexity follows from the equivalence of the sequential and recursive formulation of the problem where the strict convexity of the value function of the sequential problem follows from strict convexity of the cost function $C$.

2. Differentiability of $V$ can now be shown (for which strict convexity of $V$ is crucial). Uniqueness of decision rules follow from strict convexity of $V$, and continuity from the theorem of the maximum.

3. These are standard first order and envelope conditions.

4. From first order conditions and strict convexity of $C$, and $V$ (in $w$ ). 
5. Current income $y$ appears in the Bellman equation only in the probabilities $\pi\left(y^{\prime} \mid y\right)$, independent of $y$ in the iid case. The properties for $w^{\prime}\left(w, y ; y^{\prime}\right)$ follow from the first order conditions and strict convexity of $V$.

The first order conditions above have easily interpretable consequences ${ }^{15}$ for consumption paths, given values for outside options $U^{\text {Out }}(\cdot)$. They imply

$$
C^{\prime}(h(y, w)) \begin{cases}=\frac{1}{\beta R} C^{\prime}\left(h\left(y^{\prime}, w^{\prime}\left(y, w ; y^{\prime}\right)\right)\right) & \text { if } w^{\prime}\left(y, w ; y^{\prime}\right)>U^{\mathrm{Out}}\left(y^{\prime}\right), \\ \leqslant \frac{1}{\beta R} C^{\prime}\left(h\left(y^{\prime}, w^{\prime}\left(y, w ; y^{\prime}\right)\right)\right) & \text { if } w^{\prime}\left(y, w ; y^{\prime}\right)=U^{\mathrm{Out}}\left(y^{\prime}\right),\end{cases}
$$

or-written in terms of consumption-

$$
u^{\prime}(c(y, w)) \begin{cases}=\beta R u^{\prime}\left(c\left(y^{\prime}, w^{\prime}\left(y, w ; y^{\prime}\right)\right)\right) & \text { if } w^{\prime}\left(y, w ; y^{\prime}\right)>U^{\mathrm{Out}}\left(y^{\prime}\right), \\ \geqslant \beta R u^{\prime}\left(c\left(y^{\prime}, w^{\prime}\left(y, w ; y^{\prime}\right)\right)\right) & \text { if } w^{\prime}\left(y, w ; y^{\prime}\right)=U^{\mathrm{Out}}\left(y^{\prime}\right)\end{cases}
$$

In particular, for $\beta R=1$, consumption never falls, but may ratchet upwards, whenever the constraint of the outside option is binding. Thus, for $\beta R=1$, consumption eventually stays constant, which is the case of "full insurance". In Section 3.4, we investigate and describe the resulting equilibrium. If $\beta R<1$, consumption keeps falling as long as the constraint of the outside option is not binding. The equilibrium for this case is investigated in Sections 3.3 and 3.5. ${ }^{16}$

Since current utility $h$ and thus current consumption $c$ are strictly increasing functions of utility promises $w$, the consumption dynamics can be perfectly deduced from the dynamics of utility promises. Before characterizing equilibrium in detail we give an overview over our findings, using three figures that plot the optimal utility promises tomorrow, $w^{\prime}\left(y^{\prime}\right)$ against utility promises today. For these figures, it has been assumed that there are two income states, $y_{1}<y_{2}$, and that income is iid. Also plotted is the expected discounted future utility promise $\beta \sum_{y^{\prime}} \pi\left(y^{\prime}\right) w^{\prime}\left(y^{\prime}\right)$, since the vertical distance of this line and the $45^{\circ}$-line amounts to current utility $(1-\beta) h=(1-\beta) u(c)$. Fig. 1 pertains to a very impatient agent (relative to the interest rate), Fig. 2 shows the case where the agent is as patient as the principal (that is, $\beta R=1$ ), and Fig. 3 exhibits an intermediate case.

In Fig. 1 the agent is very impatient, relative to the interest rate. For low $\beta$ it is optimal for the principal to give high current utility $(1-\beta) u(c)$ and low continuation utilities, subject to the constraints $w^{\prime}\left(y^{\prime}\right) \geqslant U^{\text {Out }}\left(y^{\prime}\right)$. For all current promises $w \in$ $\left[U^{\text {Out }}\left(y_{1}\right), U^{\text {Out }}\left(y_{2}\right)\right]$ the continuation promises are always at the constraint: $w^{\prime}\left(y^{\prime}\right)=U^{\text {Out }}\left(y^{\prime}\right)$. An agent starting with current promises $w=U^{\text {Out }}\left(y_{2}\right)$ (point A), upon receiving one bad shock moves to $w^{\prime}=U^{\text {Out }}\left(y_{1}\right)$ (point $\mathrm{B}$ via $\mathrm{C}$ ), and an agent with one

\footnotetext{
${ }^{15} \mathrm{We}$ are grateful to a careful referee for suggesting this perspective.

${ }^{16} \mathrm{It}$ is worth mentioning that for the properties of the insurance contract only the relation between $\beta$ and $1 / R$ matters, but not the absolute value of $\beta<1$. This is in contrast to models with exogenous outside option given by autarky. In these models there is a threshold $\bar{\beta}<1$ such that autarky is so bad for discount factors above this level (because the lack of future insurance becomes more and more severe) that perfect insurance can be enforced by the threat of exclusion. Here perfect insurance (only in the limit) is obtained only if $R \beta=1$, independent of the absolute level of $\beta$. Whereas in the model with exogenous outside option only $\beta$ determines the value of this option, in our model both $\beta$ and $R$ matter for it, since the latter determines the present discounted value of the endowment stream.
} 


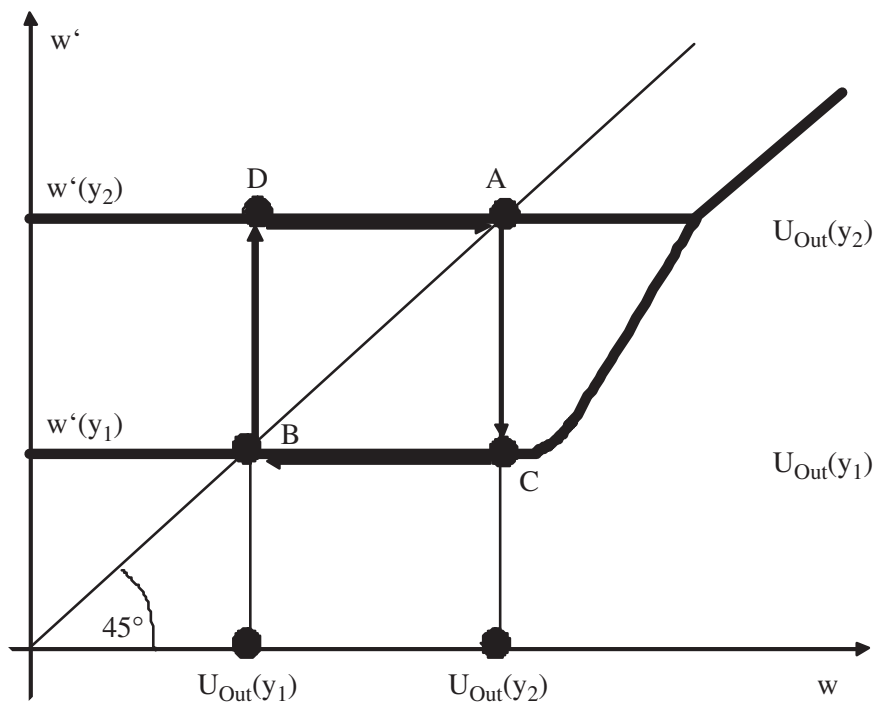

Fig. 1. No insurance.

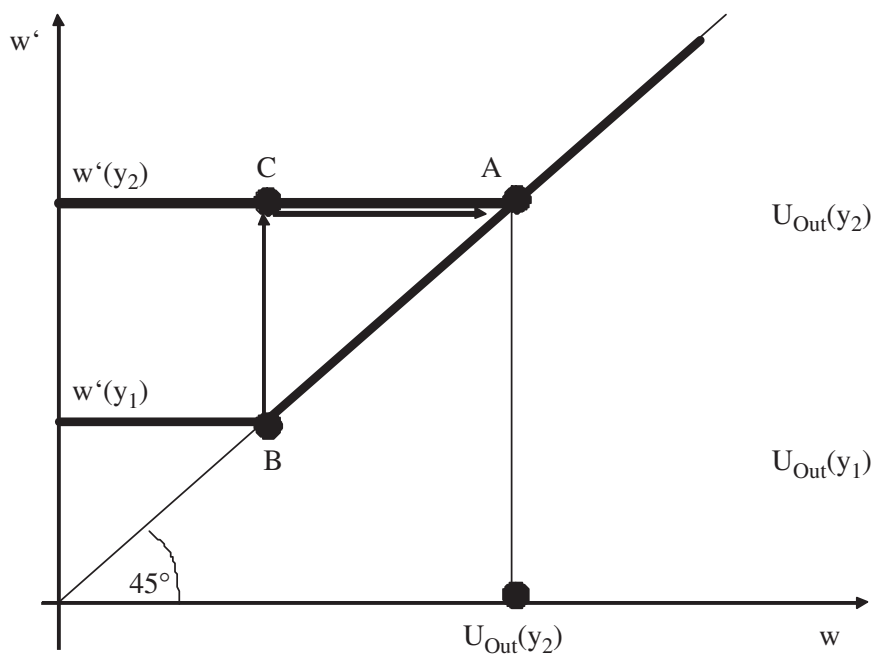

Fig. 2. Full insurance.

good shock moves from point B to A (via D). Note that agents, at no point in the contract, have continuation utility higher than their outside option (i.e. the principal does not share risk with the agent). We will show in Section 3.3 that for a sufficiently low $\beta R$ the stationary equilibrium is autarky: the equilibrium outside options equal the utility obtained consuming the endowment in each period, the allocation equals the autarkic allocation, and the stationary promise distribution has only positive mass $\Pi(y)$ at $U^{\text {Out }}(y)$.

Fig. 2 depicts the other extreme, with $\beta R=1$. Now it is beneficial for the principal to economize on current utility and give high utility promises from tomorrow onwards. 


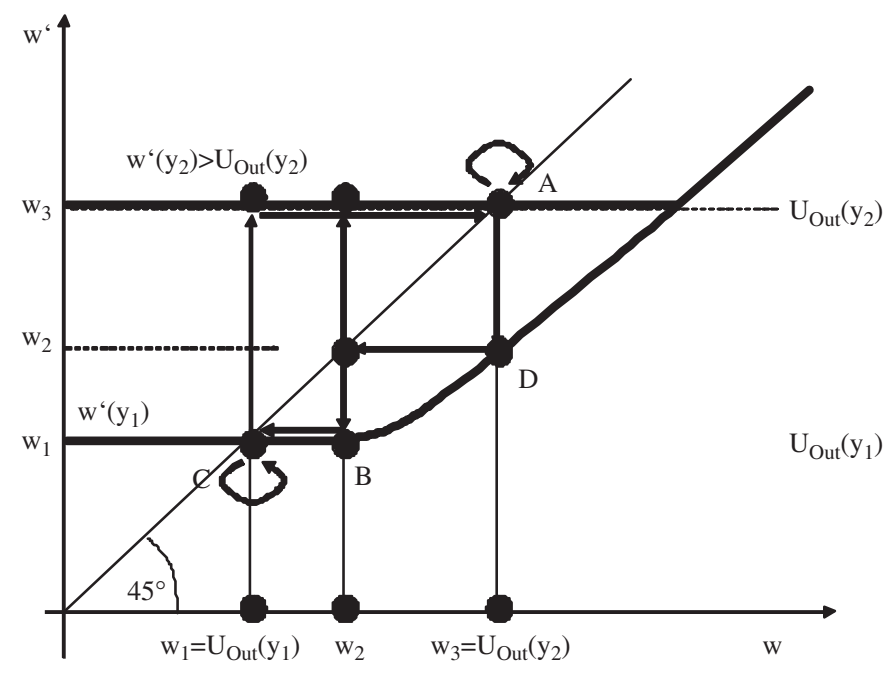

Fig. 3. Partial insurance.

For iid income shocks future promises coincide with the $45^{\circ}$-line whenever $w \geqslant U^{\text {Out }}\left(y^{\prime}\right)$ and are constrained by $U^{\mathrm{Out}}\left(y^{\prime}\right)$ below these points. It is easy to see (we will formalize this in Section 3.4) that, as the agent experiences good income shocks, continuation utility and future consumption move up (to $U^{\text {Out }}\left(y_{\max }\right)$ and the corresponding consumption level) and stay there forever: eventually an agents' consumption is perfectly smooth as he obtains complete consumption insurance.

Finally, Fig. 3 shows an intermediate case in which partial insurance obtains. Consider an agent with current utility promise $w=U^{\text {Out }}\left(y_{2}\right)$ (point A). If this agent experiences a bad income shock $y^{\prime}=y_{1}$ her future utility promise $w^{\prime}\left(y^{\prime}\right)$ is lower than today's promise (and the same is true for consumption). However, the drop in promises and consumption is not as drastic as in Fig. 1: now it takes two bad income shocks to hit $U^{\text {Out }}\left(y_{1}\right)$ (from point A via $\mathrm{D}$ to $\mathrm{B}$ ). Thus, the agent is partially insured against income risk. However, in contrast to Fig. 2 insurance is not perfect: utility promises and consumption drop with a low income realization, even for an agent that previously had worked herself up to point A. For the iid case with two income shocks, Section 3.5 below will provide a complete characterization of the consumption dynamics, including the optimal number and size of downward consumption steps shown in Fig. 3.

\subsection{Existence and properties of equilibrium}

In this section we establish general properties of our model. If Condition 1 is satisfied, existence of an equilibrium can be guaranteed.

Proposition 5. Let Condition 1 be satisfied. Then an optimal contract and outside options $\left\{U^{\text {Out }}(y)\right\}_{y \in Y}$ satisfying (14) exist. Furthermore, an equilibrium exists.

Proof. Again we defer details to the technical appendix. There we first prove that there exist outside options $U^{\text {Out }}=\left(U^{\text {Out }}\left(y_{1}\right), \ldots, U^{\text {Out }}\left(y_{m}\right)\right)$ and associated value and policy functions $V_{U^{\mathrm{Out}}}, h_{U^{\mathrm{Out}}}, w_{U^{\mathrm{Out}}}^{\prime}\left(y^{\prime}\right)$ of the principals solving $V_{U^{\mathrm{Out}}}\left(y, U^{\mathrm{Out}}(y)\right)=a(y)$ for all $y$. 
Then we prove that the Markov transition function induced by $\pi$ and $w_{U}^{\prime}{ }_{\text {Out }}\left(y^{\prime}\right)$ has a stationary distribution.

For the first part define the function $f:[\underline{w}, \bar{w}]^{m} \rightarrow[\underline{w}, \bar{w}]^{m}$ by

$$
f_{j}\left[U^{\text {Out }}\right]=\min \left\{\tilde{w} \in[\underline{w}, \bar{w}]: V_{U^{\text {Out }}}\left(y_{j}, \tilde{w}\right) \geqslant a\left(y_{j}\right)\right\} \quad \text { for all } j=1, \ldots, m .
$$

We need to show three things: (1) the function $f$ is well-defined on all of $[\underline{w}, \bar{w}]^{m},(2)$ the function $f$ is continuous, (3) any fixed point $w^{*}$ of $f$ satisfies $V_{w^{*}}\left(y_{j}, w_{j}^{*}\right)=a\left(y_{j}\right)$ for all $j=1, \ldots, m$. Part 1 is straightforward. ${ }^{17}$ Part (2) requires to show that the cost function $V_{U}$ Out $\left(.\right.$, .) is uniformly continuous in the outside options $U^{\text {Out }}$ (which is involved, but not conceptually difficult, and for which Assumption 1 is again needed assure that the cost function is well-defined for all possible outside options $U^{\text {Out }}$ ). Finally, part (3) has to rule out that at the fixed point of $f$ we have $V_{w^{*}}\left(y_{j}, w^{*}\right)>a\left(y_{j}\right)$, which is done by constructing an allocation that attains lifetime utility $w^{*}$ at costs lower than $V_{w^{*}}$ (which is nontrivial and again requires Condition 1).

For the second part we establish that $\pi$ and $w^{\prime}\left(y, w ; y^{\prime}\right)$ indeed induce a well-defined Markov transition function which satisfies the Feller property. The fact that $w^{\prime}$ is continuous in $w$ assures this. Then Theorem 12.10 in Stokey et al. (1989) guarantees the existence of a stationary measure $\Phi$ (although not its uniqueness).

The following proposition says that the contracts cannot be too generous at the sign-up date and thus demonstrates the general result in our environment that the insurance contracts require a nonnegative pre-payment or contract initiation fee. The proposition is also useful for further characterizing the equilibrium below (e.g. in Proposition 11).

Proposition 6. It cannot be the case that $c\left(y, U^{\mathrm{Out}}(y)\right)>y$ for any $y \in Y$.

Proof. Suppose that $c\left(\hat{y}, U^{\mathrm{Out}}(\hat{y})\right)>\hat{y}$. Eq. (6) becomes

$$
\begin{aligned}
V\left(\hat{y}, U^{\text {Out }}(\hat{y})\right) & =\left(1-\frac{1}{R}\right) c\left(\hat{y}, U^{\text {Out }}(\hat{y})\right)+\frac{1}{R} \sum_{y^{\prime} \in Y} \pi\left(y^{\prime} \mid \hat{y}\right) V\left(y^{\prime}, w^{\prime}\left(\hat{y}, U^{\text {Out }}(\hat{y}) ; y^{\prime}\right)\right) \\
& >\left(1-\frac{1}{R}\right) \hat{y}+\frac{1}{R} \sum_{y^{\prime} \in Y} \pi\left(y^{\prime} \mid \hat{y}\right) V\left(y^{\prime}, U^{\text {Out }}\left(y^{\prime}\right)\right) \\
& =\left(1-\frac{1}{R}\right) \hat{y}+\frac{1}{R} \sum_{y^{\prime} \in Y} \pi\left(y^{\prime} \mid \hat{y}\right) a\left(y^{\prime}\right)=a(\hat{y}) .
\end{aligned}
$$

The inequality in the equation follows from the assumption and the fact that $\left.w^{\prime}\left(\hat{y}, U^{\text {Out }}(\hat{y}) ; y^{\prime}\right) \geqslant U^{\text {Out }}\left(y^{\prime}\right)\right)$ by the participation constraint of the agent as well as the fact that $V$ is strictly increasing (as shown in Proposition 4). But this is a contradiction to $(10)$.

The following property is interesting, intuitive and also useful for the analysis to follow. It says, that an agent cannot be made better off by waiting in autarky for one more period before signing up to a contract.

\footnotetext{
${ }^{17}$ Note, however, that the more natural definition of $f$ as

$$
\left.V_{U^{\text {Out }}}\left(y_{j}, f_{j}\left[U^{\text {Out }}\right]\right)=a\left(y_{j}\right)\right\} \quad \text { for all } j=1, \ldots, m,
$$

would have made it impossible to show that $f$ is well-defined on all of $[\underline{w}, \bar{w}]$, unless very restrictive assumptions on $[\underline{w}, \bar{w}]$ are made.
} 


\section{Proposition 7.}

$$
U^{\mathrm{Out}}(y) \geqslant(1-\beta) u(y)+\beta \sum_{y^{\prime} \in Y} \pi\left(y^{\prime} \mid y\right) U^{\mathrm{Out}}\left(y^{\prime}\right) .
$$

Proof. Let

$$
\hat{w}=(1-\beta) u(y)+\beta \sum_{y^{\prime} \in Y} \pi\left(y^{\prime} \mid y\right) U^{\mathrm{Out}}\left(y^{\prime}\right) .
$$

Consider a principal who offers consumption $c=y$ and continuation utilities $w^{\prime}\left(y^{\prime}\right)=$ $U^{\text {Out }}\left(y^{\prime}\right)$ to an agent entitled to the promise $\hat{w}$, using the cost minimizing contract from tomorrow onwards. With Eqs. (10) and (9), the cost $\tilde{V}$ of this contract is

$$
\tilde{V}=\left(1-\frac{1}{R}\right) y+\frac{1}{R} \sum_{y^{\prime} \in Y} \pi\left(y^{\prime} \mid y\right) a\left(y^{\prime}\right)=a(y) .
$$

Thus, $V(y, \hat{w}) \leqslant a(y)$ and therefore $U^{\text {Out }}(y) \geqslant \hat{w}$.

A useful property of the equilibrium for our further analysis is that the outside option of an agent is an increasing function of his income.

Proposition 8. Suppose the income process is iid. Then in any equilibrium $U^{\mathrm{Out}}(y)$ is strictly increasing in $y$.

Proof. $U^{\text {Out }}(y)$ solves $V\left(U^{\text {Out }}(y)\right)=a(y)$. The result follows since $a(y)$ is strictly increasing in $y$ and since $V(w)$ is increasing in $w{ }^{18}$

\subsection{No risk sharing: autarky}

For the remainder of this section we assume that $v(y) \equiv 0$, that is, there are no direct costs of switching intermediaries. As a starting point of our characterization of equilibrium, we shall analyze conditions, under which the principals do not have to make net payments in the long run, i.e. we seek equilibria which also deliver the following condition: ${ }^{19}$

Definition 9 (Nonnegative steady state cash flow condition).

$$
\gamma=\int(y-V(y, w)) \mathrm{d} \Phi \geqslant 0 .
$$

Leaving a location has no consequences for an agents' ability to engage in future risk sharing arrangements and generates no cost other than giving up current promises $w$. One may interpret the promise $w$ as relationship capital: the principal guarantees a particular

\footnotetext{
${ }^{18}$ One may think that this proposition can be proved with the weaker condition that $\pi(. \mid y)$ first oder stochastically dominates $\pi(. \mid \hat{y})$ if $y>\hat{y}$. Under this assumption $a(y)$ is still strictly increasing in $y$ and $V(y, w)$ is still increasing in $w$. But if $V(y, w)$ is strictly increasing in $y$ (which we verified numerically to often be the case), the result does not follow.

${ }^{19}$ An alternative interpretation of this condition is to view $y$ as contributions to bank or pension account with a financial intermediary, and consumption allocations as withdrawals from that account. Then $V(y, w)$ measures the present discounted value of all future withdrawals. The condition then requires that in the steady state contributions to be at least as large as withdrawals. In other words, the condition requires the steady state value of assets already in the account to be nonpositive.
} 
level of happiness to the agent as a consequence of past events. Our first proposition shows that the threat of losing this goodwill is not enough to support risk sharing, if the principals need to enjoy nonnegative cash flow in steady state.

Proposition 10. Assume $v(y) \equiv 0, y \in Y$.

1. If an equilibrium satisfies the nonnegative steady state profit condition, then it has to implement the autarkic allocation almost everywhere (a.e.):

$$
c(y, w)=y, \quad \Phi-\text { a.e. }
$$

2. Conversely, if an equilibrium implements the autarkic allocation, then the nonnegative steady state profit condition is satisfied.

Proof. Remember that in any equilibrium $V(y, w)$ has to be weakly increasing in $w$. For $(y, w) \in \operatorname{supp} \Phi$, we must have $w \geqslant U^{\text {Out }}(y)$ and thus

$$
V(y, w) \geqslant V\left(y, U^{\mathrm{Out}}(y)\right)=a(y) .
$$

On the other hand, the assumed nonnegativity of $\gamma$ together with

$$
\sum_{y \in Y} a(y) \Pi(y)=\sum_{y \in Y} y \Pi(y)=E[y]
$$

implies

$$
\int V(y, w) \mathrm{d} \Phi \leqslant E[y]=\int a(y) \mathrm{d} \Phi .
$$

Together,

$$
V(y, w)=a(y), \quad \Phi \text {-a.e. }
$$

Now, comparing the two equations

$$
\begin{aligned}
& V(y, w)=\left(1-\frac{1}{R}\right) c(y, w)+\frac{1}{R} \sum_{y^{\prime}} \pi\left(y^{\prime} \mid y\right) V\left(y^{\prime}, w^{\prime}\left(y, w ; y^{\prime}\right)\right) \\
& a(y)=\left(1-\frac{1}{R}\right) y+\frac{1}{R} \sum_{y^{\prime}} \pi\left(y^{\prime} \mid y\right) a\left(y^{\prime}\right)
\end{aligned}
$$

shows that $c(y, w)=y$, almost everywhere. The second part of the proposition follows trivially from the definitions

The equilibrium distribution $\Phi$ in Proposition 10 is easy to calculate. Since agents consume their endowment, it follows that their remaining lifetime utility is given by the continuation utility from consuming the stochastic income stream in each period, starting with current income $y$. This utility from "autarky" $w_{\text {aut }}(y)$ is recursively defined as

$$
w_{\text {aut }}(y)=(1-\beta) u(y)+\beta \sum_{y^{\prime} \in Y} \pi\left(y^{\prime} \mid y\right) w_{\text {aut }}\left(y^{\prime}\right) .
$$

The distribution $\Phi$ therefore assigns weight $\Pi(y)$ to the atoms $\left(y, w_{\text {aut }}(y)\right)$ and zero to everything else. Proposition 10 says that any equilibrium must necessarily have $c\left(y, w_{\text {aut }}(y)\right)=y$ for all $y \in Y$. Similarly, the promised utility at these points is obviously $w^{\prime}\left(y, w_{\text {aut }}(y) ; y^{\prime}\right)=w_{\text {aut }}\left(y^{\prime}\right)$. Comparing the result above to the definition of an equilibrium, 
we see that the proposition does not yet deliver the full specification required for a stationary equilibrium. Such a specification requires the consumption function as well as all other functions listed in the equilibrium definition to be defined on the set $Z=$ $Y \times[\underline{w}, \bar{w}]$ rather than just the support of $\Phi$. If we restricted the domain $Z$ to just include the support of $\Phi$, Proposition 10 would essentially establish that we always have an equilibrium implementing autarky. With that assumption, the principals would have no choice but to implement the autarky solution! They would not be allowed to deviate from the autarky utility promises, even if they preferred to do so. Or, assume instead that $Z=\{(y, \bar{w}) \mid y \in Y\}$ where $\bar{w}=u(E[y])$ is the utility promise from complete risk sharing. In that case, principals would have no choice but to always implement the complete risk sharing solution. Thus, choices of the domain $Z$ of this type would completely predetermine the outcome.

Now we aim at constructing the equilibrium contract on the entire set $Z=Y \times[\underline{w}, \bar{w}]$. This requirement of the equilibrium turns out to have bite in that it rules out the existence of equilibria satisfying the nonnegative steady state cash flow condition for some $R$ altogether and leads to the explicit and unique construction of the equilibrium functions outside the support of $\Phi$ otherwise. Indeed, in part 3.4, where we dispense with the nonnegativity of cash flow, we shall obtain complete risk sharing if $R \beta=1$ and income is iid. This is obviously squarely at odds with the autarky result above. The next proposition shows, that no equilibrium satisfying the nonnegative cash flow in steady state condition exists for $R \beta=1$, thus resolving this conflict.

For the autarky result to hold we need to rule out that a principal would find it profitable to deviate from an equilibrium in which all other principals offer the autarky contract: this can be achieved under the assumption that the principal is sufficiently patient (interest rates are low enough). Intuitively, deviating from the autarky solution involves offering a agent with a high income now a better contract by taking some of his current endowment for the promise of additional consumption goods in future periods, when his endowment is low. A principal facing sufficiently low interest rates is deterred by the future costs of sticking to such a contract. Based on this argument, we expect there to be an upper bound on the interest rate $R$ for the autarky result to emerge.

Our next result below shows that this is indeed the case. ${ }^{20}$ Define

$$
h_{\mathrm{aut}}(y, w)=\frac{w-\beta \sum_{y^{\prime} \in Y} \pi\left(y^{\prime} \mid y\right) w_{\mathrm{aut}}\left(y^{\prime}\right)}{1-\beta} .
$$

Note that $h_{\text {aut }}\left(y, w_{\text {aut }}(y)\right)=u(y)$, see Eq. (40). Define

$$
\bar{w}_{m}(y)=\max \left\{w \mid C\left(h_{\text {aut }}(y, w)\right) \leqslant y_{m}\right\} .
$$

Proposition 11. Assume that Condition 1 holds.

1. An equilibrium satisfying the nonnegative steady state cash flow condition exists, if and only if

$$
R \in(1, \bar{R}]
$$

\footnotetext{
${ }^{20} \mathrm{We}$ are grateful to a careful referee for correcting an earlier version of this proposition and suggesting the proof strategy to us.
} 
where

$$
\bar{R}=\frac{1}{\beta} \frac{C^{\prime}\left(u\left(y_{1}\right)\right)}{C^{\prime}\left(u\left(y_{m}\right)\right)}=\frac{1}{\beta} \frac{u^{\prime}\left(y_{m}\right)}{\left.u^{\prime}\left(y_{1}\right)\right)} .
$$

Moreover, no equilibria exist that violate the nonnegative steady state cash flow condition, if condition (44) is satisfied.

2. Given condition (44), the equilibrium has the following form for $y \in Y$ and $w \leqslant \bar{w}_{m}(y)$,

$$
\begin{aligned}
& V(y, w)=\left(1-\frac{1}{R}\right)\left(C\left(h_{\mathrm{aut}}(y, w)\right)-y\right)+a(y), \\
& c(y, w)=C\left(h_{\mathrm{aut}}(y, w)\right), \\
& w^{\prime}\left(y, w ; y^{\prime}\right)=w_{\mathrm{aut}}\left(y^{\prime}\right), \\
& U^{\text {Out }}(y)=w_{\text {aut }}(y),
\end{aligned}
$$

cash flow $\gamma=0$ and a positive measure $\Phi$ as constructed above. ${ }^{21}$

3. Suppose that $\beta R=1$. Then, no equilibrium satisfying the nonnegative steady state cash flow condition exists.

\section{Proof.}

1. (a) Suppose that $R>\bar{R}$ and assume that an equilibrium satisfies the nonnegative cash flow condition. Now take $y=y_{m}, w=U^{\text {Out }}\left(y_{m}\right)$ and $y^{\prime}=y_{1}$. Proposition 10 implies that $w^{\prime}\left(y_{m}, w ; y_{1}\right)=U^{\text {Out }}\left(y_{1}\right)$. Furthermore, it implies that

$$
\begin{aligned}
& c\left(y_{1}, w^{\prime}\left(y_{m}, w ; y_{1}\right)\right)=c\left(y_{1}, U^{\mathrm{Out}}\left(y_{1}\right)\right)=y_{1}, \\
& c\left(y_{m}, U^{\mathrm{Out}}\left(y_{m}\right)\right)=y_{m} .
\end{aligned}
$$

But then

$$
\begin{aligned}
u^{\prime}\left(y_{m}\right) & =u^{\prime}\left(c\left(y_{m}, U^{\mathrm{Out}}\left(y_{m}\right)\right) \geqslant \beta R u^{\prime}\left(c\left(y_{1}, w^{\prime}\left(y_{m}, U^{\mathrm{Out}}\left(y_{m}\right) ; y_{1}\right)\right)\right)\right. \\
& >\beta \bar{R} u^{\prime}\left(c\left(y_{1}, w^{\prime}\left(y_{m}, U^{\mathrm{Out}}\left(y_{m}\right) ; y_{1}\right)\right)\right)=\frac{u^{\prime}\left(y_{m}\right)}{u^{\prime}\left(y_{1}\right)} u^{\prime}\left(y_{1}\right)
\end{aligned}
$$

a contradiction. Here the first equality is due to Eq. (50), the first inequality due to Eq. (26), the second inequality due to the assumption $R>\bar{R}$ and the last equality comes from the definition of $\bar{R}$. Thus, an equilibrium satisfying the nonnegative cash flow condition cannot exist if $R>\bar{R}$.

(b) Conversely, suppose that $R \leqslant \bar{R}$. The proof proceeds in two steps, with the first providing an important auxiliary result.

(i) Take an arbitrary $(y, w)$ with $c(y, w)<y$. We want to show that then $w<U^{\text {Out }}(y)$. For any $y^{\prime} \in Y$ either $w^{\prime}\left(y, w ; w^{\prime}\right)=U^{\text {Out }}\left(y^{\prime}\right)$ or $w^{\prime}\left(y, w ; w^{\prime}\right)>U^{\text {Out }}\left(y^{\prime}\right)$. In the later case by the assumption $R \leqslant \bar{R}$, the definition of $\bar{R}$ and Eq. (26)

$$
\beta R u^{\prime}\left(y_{1}\right) \leqslant \beta \bar{R} u^{\prime}\left(y_{1}\right)=u^{\prime}\left(y_{m}\right) \leqslant u^{\prime}(y)<u^{\prime}(c(y, w))=\beta R u^{\prime}\left(c\left(y^{\prime}, w^{\prime}\left(y, w ; y^{\prime}\right)\right)\right.
$$

\footnotetext{
${ }^{21}$ Due to Eq. (26) and the low value for $R$, see (44), a contract offering consumption $c=y_{m}$ and autarky from next period onwards cannot be improved upon. For promise levels $w>\bar{w}_{m}(y)$ implying higher consumption levels, one may need several "steps" to reach the autarky solution, but will get there eventually. It is not hard, but tedious and not particularly insightful to spell out the contractual details also for these initial high levels of promises.
} 
and thus $c\left(y^{\prime}, w^{\prime}\left(y, w ; w^{\prime}\right)<y^{\prime}\right.$. Thus, consumption remains below income tomorrow or $w^{\prime}\left(y, w ; w^{\prime}\right)=U^{\text {Out }}\left(y^{\prime}\right)$. Consequently, iterating on the promise keeping constraint from tomorrow on we have $w^{\prime}\left(y^{\prime}\right) \leqslant U^{\text {Out }}\left(y^{\prime}\right)$. Thus,

$$
\begin{aligned}
w & =(1-\beta) u(c(y, w))+\beta \sum_{y^{\prime} \in Y} \pi\left(y^{\prime} \mid y\right) w^{\prime}\left(y, w ; y^{\prime}\right) \\
& <(1-\beta) u(y)+\beta \sum_{y^{\prime} \in Y} \pi\left(y^{\prime} \mid y\right) U^{\mathrm{Out}}\left(y^{\prime}\right) \leqslant U^{\mathrm{Out}}(y),
\end{aligned}
$$

where the last inequality is due to (29).

(ii) The previous result implies that for all $y$ we have $c\left(y, U^{\mathrm{Out}}(y)\right) \geqslant y$. Then Proposition 6 implies that $c\left(y, U^{\text {Out }}(y)\right)=y$ for all $y$. We finally show that $R \leqslant \bar{R}$ and $c\left(y, U^{\text {Out }}(y)\right)=y$ for all $y$ imply that the equilibrium satisfies the nonnegative steady state cash flow condition (note that existence of equilibrium is guaranteed by Proposition 5, and is constructed in the second part of this proof). To that end, pick an arbitrary $(y, w) \in \operatorname{supp} \Phi$. To simplify the argument, ${ }^{22}$ assume that $\Phi$ assigns positive mass to the point $(\tilde{y}, \tilde{w})$. Thus, there must be some other state $(\hat{y}, \hat{w}) \in \operatorname{supp} \Phi$, say, for which $\tilde{w}=w^{\prime}(\hat{y}, \hat{w} ; \tilde{y})$. As a consequence, $\tilde{w} \geqslant U^{\text {Out }}(\tilde{y})$, since the participation constraint must be satisfied for continuation promises.

With Proposition 10, we are done if we can show that $c(\tilde{y}, \tilde{w})=\tilde{y}$, since then the autarkic allocation is implemented. Suppose not. By the first step and by virtue of $\tilde{w} \geqslant U^{\mathrm{Out}}(\tilde{y})$, it must then be the case that $c(\tilde{y}, \tilde{w})>\tilde{y}$. Choose $\varepsilon>0$ such that $c(y, w)>c\left(y^{\prime}, w^{\prime}\right)+\varepsilon$ for all $(y, w),\left(y^{\prime}, w^{\prime}\right) \in \operatorname{supp} \Phi$ that satisfy

$$
u^{\prime}(c(y, w))=\beta R u^{\prime}\left(c\left(y^{\prime}, w^{\prime}\right)\right) .
$$

Since $\beta R<1$ and supp $\Phi$ is compact, it is easy to see that such an $\varepsilon>0$ exists. Without loss of generality, ${ }^{23}$ assume that $(\tilde{y}, \tilde{w})$ has been chosen such that

$$
c(\tilde{y}, \tilde{w})>\sup \{c(y, w) \mid(y, w) \in \operatorname{supp} \Phi, c(y, w)>y\}-\varepsilon .
$$

Note that $\tilde{w}>U^{\mathrm{Out}}(\tilde{y})$, since otherwise $c(\tilde{y}, \tilde{w})=\tilde{y}$. Eq. (26) then implies

$$
u^{\prime}(c(\hat{y}, \hat{w}))=\beta R u^{\prime}(c(\tilde{y}, \tilde{w})) .
$$

By assumption about $\varepsilon$, this implies $c(\hat{y}, \hat{w})>c(\tilde{y}, \tilde{w})+\varepsilon$. By choice of $(\tilde{y}, \tilde{w})$, it therefore must be the case that $c(\hat{y}, \hat{w})=\hat{y}$ (otherwise $(\tilde{y}, \tilde{w})$ would not have satisfied (55)) . But this leads to the contradiction

$$
\begin{aligned}
\beta R u^{\prime}\left(y_{1}\right) & \leqslant \beta \bar{R} u^{\prime}\left(y_{1}\right)=u^{\prime}\left(y_{m}\right) \leqslant u^{\prime}(\hat{y}) \\
& =u^{\prime}(c(\hat{y}, \hat{w}))=\beta R u^{\prime}(c(\tilde{y}, \tilde{w})) \\
& <\beta R u^{\prime}(\tilde{y}) \leqslant \beta R u^{\prime}\left(y_{1}\right) .
\end{aligned}
$$

Thus, the equilibrium satisfies the nonnegative steady state cash flow condition.

\footnotetext{
${ }^{22}$ Providing the argument for nonatomistic measures is not much harder and exploits the continuity of the policy function $c(y, w)$ in $w$, but is tedious and adds little in terms of insights.

${ }^{23}$ We need to demonstrate a contradiction for one $(\tilde{y}, \tilde{w}) \in \operatorname{supp} \Phi$ satisfying $c(\tilde{y}, \tilde{w})>\tilde{y}$.
} 
2. The fact that $U^{\text {Out }}(y)=w_{\text {aut }}(y)$ follows from $c\left(y, U^{\text {Out }}(y)\right)=y$ for all $y$. Condition (44) then implies that $w^{\prime}\left(y, w ; y^{\prime}\right)=w_{\text {aut }}\left(y^{\prime}\right)$ for all $w \leqslant \bar{w}_{m}(y)$. The promise-keeping constraint then implies that $h=h(y, w)$ must be as in Eq. (41) for $w \leqslant \bar{w}_{m}(y)$. The consumption function $c$ follows from the definition of $C($.). Once this function is known, the value function implied by $c(y, w)$ can be easily calculated.

3. Follows from the first part.

Note that condition (44) is essentially the same as the one stated in Krueger and Perri (1999): in their environment with endogenous gross interest rate $R$, risk sharing can only be obtained if $(1 / \beta)\left(u^{\prime}\left(y_{m}\right) / u^{\prime}\left(y_{1}\right)\right)<1$, whereas autarky obtains if $(1 / \beta)\left(u^{\prime}\left(y_{m}\right) u^{\prime}\left(y_{1}\right)\right) \geqslant 1$.

\subsection{Perfect risk sharing: full insurance in the limit}

Now consider the case $\beta R=1$ in Fig. 2. If the agent is already at point $A$ with high current promises $w=U^{\text {Out }}\left(y_{2}\right)$, she will stay there, no matter which income she receives in the future. If the agent is at point $B$, she will stay there as long as income is low, $y_{t}=y_{1}$. But the first time the agent receives high income $y_{2}$, she jumps to point $C$ on the $w^{\prime}\left(y_{2}\right)$-branch and then stays at point $A$ forever, with constant utility promises and consumption. The same is true for an agent with initial utility promise $w \in\left(U^{\mathrm{Out}}\left(y_{1}\right), U^{\mathrm{Out}}\left(y_{2}\right)\right)$. We call this full insurance in the limit: full insurance is not obtained upon entering the contract, but eventually, with probability one. The stationary distribution is a unit point mass at $U^{\text {Out }}\left(y_{2}\right)$, reflecting the fact that eventually all agents are fully insured against income fluctuations. We now prove these claims formally. First, we demonstrate that full insurance obtains if and only if $\beta R=1$.

Proposition 12. Suppose income is iid with probabilities $\pi\left(y_{i}\right)>0$.

1. Suppose that $\beta R=1$. Then any optimal contract implies full insurance in the limit, i.e. constant consumption from the first time that the highest income level $y_{m}$ is realized.

(a) The utility promises take the form $w^{\prime}\left(w ; y^{\prime}\right)=\max \left(w, U^{\mathrm{Out}}\left(y^{\prime}\right)\right)$.

(b) The decision rule for current utility $h=h(w)$ is defined by (5). The cost function $V(w)$ satisfies $V^{\prime}(w)=C^{\prime}(h(w))$ and $V(w)=C(w)$ for $w \geqslant \max _{y} U^{\text {Out }}(y)$.

(c) The consumption level $c_{i}$ of an agent who, so far in his life, had maximal income $y_{i}$ is given by

$$
c_{i}=a\left(y_{i}\right)-\frac{1}{R-1} \sum_{j>i} \pi\left(y_{j}\right)\left[a\left(y_{j}\right)-a\left(y_{i}\right)\right] .
$$

The equilibrium outside options $U^{\mathrm{Out}}\left(y_{i}\right)$ satisfy the recursion

$$
U^{\text {Out }}\left(y_{i}\right)=\frac{(1-\beta) u\left(c_{i}\right)+\beta \sum_{j>i} \pi\left(y_{j}\right) U^{\text {Out }}\left(y_{j}\right)}{(1-\beta)+\beta \sum_{j>i} \pi\left(y_{j}\right)},
$$

with $U^{\mathrm{Out}}\left(y_{m}\right)=u\left(c_{m}\right)$. Current utility is given by

$$
h_{i}=(1-\beta) u\left(c_{i}\right) \text {. }
$$

(d) If $n=2$, then

$$
c_{2}=\left(1-\frac{1}{R}\right) y_{2}+\frac{1}{R} E[y]
$$


and

$$
c_{1}=y_{1} .
$$

2. Conversely, suppose there is full insurance in the limit and $\beta R \leqslant 1$. Then, $\beta R=1$.

Proof. 1. The first part follows directly from Proposition 4, the fact that income is iid and the assumption that $\beta R=1$. The other parts follow from the first part which implies that the contract is like a "ratchet": once some level $w_{i}$ of utility promises is reached, the promise will not fall, and will rise to $w_{j}$, if $y=y_{j}$ and $j>i$. Define $V_{i}=V\left(U^{\text {Out }}\left(y_{i}\right)\right)$ and $c_{i}$ to be the consumption level associated with $w_{i}=U^{\text {Out }}\left(y_{i}\right)$. These satisfy

$$
V_{i}=\left(1-\frac{1}{R}\right) c_{i}+\frac{1}{R}\left(\sum_{j>i} \pi\left(y_{j}\right) V_{j}+V_{i} *\left(1-\sum_{j>i} \pi\left(y_{j}\right)\right)\right) .
$$

Substituting $V_{i}=a\left(y_{i}\right)$ and solving for $c_{i}$ delivers (58). Eqs. (59)-(62) follow from simple calculations.

2. Full insurance in the limit implies, that for some $\tilde{w} \in[\underline{w}, \bar{w}]$, one has $w^{\prime}\left(\tilde{w} ; y^{\prime}\right) \equiv \tilde{w}$ for all $y^{\prime}$. Suppose $\beta R<1$. The first order conditions imply that $w^{\prime}\left(w ; y^{\prime}\right)<w$ whenever the constraint $w^{\prime}\left(w ; y^{\prime}\right) \geqslant U^{\text {Out }}\left(y^{\prime}\right)$ does not bind. But $U^{\text {Out }}\left(y_{1}\right)<U^{\text {Out }}\left(y_{m}\right)$, so it cannot be the case that all constraints bind and $w^{\prime}\left(\tilde{w} ; y_{1}\right)=w^{\prime}\left(\tilde{w} ; y_{m}\right)$; a contradiction.

The proposition shows that on the equilibrium path of the contract, an agent receives consumption $c_{i}$, where $y_{i}$ is the maximal income since starting the contract. The agent "ratches" herself up a ladder of permanent consumption claims. At the highest level of income, the agent receives consumption equal to the permanent income at that point,

$$
c_{m}=a\left(y_{m}\right)=\left(1-\frac{1}{R}\right) y_{m}+\frac{1}{R} E[y] .
$$

Note that $E[y]<c_{m}<y_{m}$. The principal receives an "up-front" payment $y_{m}-c_{m}$ for which he provides the permanent consumption level $c_{m}$ at an expected steady state loss $E[y]-c_{m}$. Since this is also the absorbing state for any contract starting with $w \leqslant U^{\text {Out }}\left(y_{m}\right)$, consumption of the principal in a stationary equilibrium equals $\gamma=E(y)-c_{m}$. For all $i<m$ we have that $c_{i}<a\left(y_{i}\right)$, i.e. the agent, in the current period, consumes even less than his expected income, where $(1 / R-1) \sum_{j>i} \pi\left(y_{j}\right)\left[a\left(y_{j}\right)-a\left(y_{i}\right)\right]$ is the insurance premium for having consumption never drop below $c_{i}$ again in the future, regardless of future income realizations. The qualitative features of our optimal contract (racheting-up of consumption, perfect insurance in the limit) are similar to those in Harris and Holmstrom's (1982) study of optimal wage contracts; in addition we provide, in an arguably simpler environment, a full characterization of the optimal risk-sharing contract. Finally, note that Eq. 58 implies that $c_{1}=y_{1}$, that is, the agent with the lowest income shock is not provided with any insurance up-front.

As an interpretation of the full insurance contract, consider observed health insurance or car insurance contracts. At the start of the contract, it often provides agents with preexisting diseases or drivers who just had an accident with no insurance at all. Only good risks (healthy people, good drivers) are given an insurance contract, pay a premium, and can then be assured of continuing coverage in the future. After the point of payment, it is no longer sensible for the agent to switch insurance agencies and pay anew. 
As a by-product of the previous proposition we can also fully characterize the stationary distribution $\Phi$ associated with complete risk sharing in the limit.

Proposition 13. Any stationary distribution $\Phi$ on $Y \times[\underline{w}, \bar{w}]$ is given by the cross product of the stationary distribution on incomes $Y$ times a distribution on $[\underline{w}, \bar{w}]$ given by a point mass on $w=U^{\mathrm{Out}}\left(y_{m}\right)$ and an arbitrary distribution $\Psi$ on the interval $\left[U^{\mathrm{Out}}\left(y_{m}\right), \bar{w}\right]$.

Proof. Follows immediately from the properties of $w^{\prime}(w ; y)$.

With any starting utility promise $w \leqslant U^{\text {Out }}\left(y_{m}\right)$, agents reach the absorbing utility promise level $U^{\text {Out }}\left(y_{m}\right)$. Agents starting at a utility promise $w>U^{\text {Out }}\left(y_{m}\right)$ will stay at that promise forever. The part $\Psi$ comes about from agents who have been given exceedingly generous utility promises from the start. If all agents in the stationary distribution started from signing up with competitive principals, then the unique stationary distribution is given by $\Phi\left(y, U^{\text {Out }}\left(y_{m}\right)\right)=\pi(y)$, and zero elsewhere.

Finally, note that the same qualitative results as above can be proved under the assumption of $\beta R>1$. Now, however, the absorbing state is the upper bound on utility promises $\bar{w}$, consumption is never declining and finally increasing to $c_{\bar{w}}$ with probability 1 . However, now $\bar{w}$ acts as a real constraint and in its absence the optimal contract (if it exists) has ever-increasing utility promises and consumption. In general, a stationary equilibrium will not exist for $\beta R>1$, which led us to focus on the case $\beta R=1$ for perfect insurance in the limit.

\subsection{Partial risk sharing}

Finally, partial insurance will obtain if

$$
\bar{R}<R<\frac{1}{\beta} .
$$

A typical situation is shown Fig. 3. Suppose, the agent starts from point $A$, i.e. high income. If income remains high, then the agent will remain at point $A$ and utility promise $w_{3}=U^{\text {Out }}\left(y_{2}\right)$. But if income is low, the agent follows the promise $D$ and point $B$ on the $w^{\prime}\left(y_{1}\right)$-branch, reaching promise $w_{2}$ next period. If income is low again, the agent finally arrives at point $C$, i.e. the agent will land a level at the utility level $w_{1}=U^{\text {Out }}\left(y_{1}\right)$. With high income at either point $B$ or at point $C$, the agent will move to the $w^{\prime}\left(y_{2}\right)$-branch, and therefore to point $A$ and utility level $w_{3}$. The stationary distribution is given by point masses on the points $\left\{w_{1}, w_{2}, w_{3}\right\}$, with probabilities resulting from the dynamics described above and the income probabilities. Depending on the parameters, there may be more points like $D$ and $B$, i.e. the dynamics may need a number of bad income draws to reach the lowest promise level $U^{\text {Out }}\left(y_{1}\right)$. The ratcheting-up part of the contract is similar to the full insurance case; but now the wedge between $\beta$ and $R$ makes consumption have a downward drift (unlike in Harris and Holmstrom, 1982) if not constrained by the outside options.

For the iid case with two income shocks we can provide a complete characterization of the consumption dynamics and the stationary consumption distributions, with the intuition provided by Fig. 3.

Proposition 14. Suppose, income can take two values $y_{1}<y_{2}$ and is iid, with $\pi=\pi\left(y_{1}\right)$, and $\beta R<1$. Then any equilibrium is characterized by a natural number $n \geqslant 2$, promise levels 
$w_{1}=U^{\mathrm{Out}}\left(y_{1}\right)<w_{2}<\cdots<w_{n-1}<w_{n}=U^{\mathrm{Out}}\left(y_{2}\right)$, costs $\quad V\left(w_{i}\right)=V_{i}, \quad V_{1}<V_{2}<\cdots<V_{n}$ and consumption levels $c_{1}<c_{2}<\cdots<c_{n}$ satisfying the following equations:

$$
\begin{aligned}
& V_{1}=a\left(y_{1}\right), \\
& V_{n}=a\left(y_{2}\right), \\
& V_{j}=\left(1-\frac{1}{R}\right) c_{j}+\frac{\pi}{R} V_{\max \{j-1,1\}}+\frac{(1-\pi)}{R} V_{n} \quad \text { for all } j=1, \ldots, n \\
& u^{\prime}\left(c_{j}^{(n)}\right)=\beta R u^{\prime}\left(c_{j-1}^{(n)}\right) \text { for } j=2, \ldots, n \\
& c_{j}=c_{j}^{(n)} \text { for } j=2, \ldots, n \\
& c_{1}=y_{1}, \\
& c_{2} \geqslant y_{1}>c_{1}^{(n)} .
\end{aligned}
$$

Proof. All equations except $c_{1}=y_{1}$ follow from the first order conditions. The result $c_{1}=y_{1}$ follows from combining the first three equations into

$$
a\left(y_{1}\right)=\left(1-\frac{1}{R}\right) c_{1}+\frac{1}{R}\left(\pi a\left(y_{1}\right)+(1-\pi) a\left(y_{2}\right)\right)
$$

and solving for $c_{1}$.

These equations can be solved reasonably easily. Iterating the third equation and combining with the first two yields, after some algebra

$$
\sum_{j=0}^{n-2}\left(\frac{\pi}{R}\right)^{j}\left(c_{n-j}-a\left(y_{2}\right)\right)=\left(\frac{\pi}{R}\right)^{n-1}\left(y_{2}-y_{1}\right),
$$

where $c_{j}, j \geqslant 2$ are found from recursively solving the Euler equations

$$
u^{\prime}\left(c_{n-j}\right)=(R \beta)^{-j} u^{\prime}\left(c_{n}\right)
$$

and therefore

$$
\begin{aligned}
c_{n-j} & =\left(u^{\prime}\right)^{-1}\left[(R \beta)^{-j} u^{\prime}\left(c_{n}\right)\right] \\
& =c_{n-j}\left(c_{n}\right)
\end{aligned}
$$

for $j=0, \ldots, n-2$. Here $\left(u^{\prime}\right)^{-1}$ is the inverse of the marginal utility function, a strictly decreasing function which maps $\mathbf{R}_{++}$into itself. Evidently

$$
c_{n}>c_{n-1}>\cdots>c_{2}
$$

and the functions $c_{n-j}\left(c_{n}\right)$ are strictly increasing and continuous in $c_{n}$. Now we characterize the consumption allocation for a fixed number of steps $n$.

Proposition 15. For any given $n \geqslant 2$ a unique solution to (68) exists. It satisfies $c_{n}=y_{2}$ for $n=2$ and $c_{n} \in\left(a\left(y_{2}\right), y_{2}\right)$ for $n>2$. Furthermore, $c_{n}$ is decreasing in $n$, strictly if $c_{2}\left(c_{n}\right)>y_{1}$.

Proof. The existence of a solution follows from the intermediate value theorem, since the left-hand side of (68) is continuous in $c_{n}$, weakly smaller than 0 for $c_{n}=a\left(y_{2}\right)$ and increasing without bound as $c_{n}$ increases, whereas the right-hand side is positive and constant in $c_{n}$. This argument also shows that $c_{n}>a\left(y_{2}\right)$. For $n=2$ (autarky) Eq. (68) immediately implies $c_{n}=c_{2}=y_{2}$. For $n>2$ (partial risk sharing) we have $c_{n}<y_{2}$ since 
otherwise the principal can never break even, since agents with bad shock $y_{1}$ get to consume more than $y_{1}$ with positive probability and agents with high shock $y_{2}$ consume $c_{n}$.

Now we show that $c_{n}$ is weakly decreasing in $n$. For fixed $n$ define $\left\{c_{n-j}^{(n)}\right\}_{j=1}^{n}$ as the sequence of consumption levels in the previous proposition. We want to show that for $n \geqslant 0$ we have $c_{n}^{(n)} \leqslant c_{n-1}^{(n-1)}$, with strict inequality if $c_{2}^{(n)}>y_{1}$. Suppose not, then $c_{n}^{(n)}>c_{n-1}^{(n-1)}$, and from $(70)$

$$
c_{n-j}^{(n)}>c_{n-j-1}^{(n-1)} \quad \text { for all } j=0, \ldots, n-3 .
$$

Denoting the left-hand side of (68) by $\Gamma(n)$ we find, using (73), that

$$
\Gamma(n-1)<\Gamma(n)-\left(\frac{\pi}{R}\right)^{n-2}\left[c_{2}^{(n)}-a\left(y_{2}\right)\right]
$$

and thus, using (68) again

$$
\left(\frac{\pi}{R}\right)^{n-2}\left[y_{2}-y_{1}\right]<\left(\frac{\pi}{R}\right)^{n-1}\left[y_{2}-y_{1}\right]-\left(\frac{\pi}{R}\right)^{n-2}\left[c_{2}^{(n)}-a\left(y_{2}\right)\right]
$$

which implies

$$
c_{2}^{(n)}<y_{1}
$$

a contradiction to the definition of $c_{2}^{(n)}$. If $c_{2}^{(n)}>y_{1}$ we can repeat the argument above to show that $c_{n}^{(n)}<c_{n-1}^{(n-1)}$.

This proposition shows the partial nature of insurance. An agent with high income $y_{2}$ consumes less than his endowment, yet more than the present discounted value of his future income. On the other hand, with bad income shocks his consumption declines only slowly, in $n-1$ steps, towards $y_{1}$. The results also show that in order for consumption to decline in many steps (a lot of insurance against bad shocks, high $n$ ), the principal, in order to break even, delivers less consumption with the good income shock: $c_{n}^{(n)}$ is decreasing in $n$.

Finally, one can characterize the optimal number of steps, $n^{*}$. From Proposition 14 we know that $c_{1}^{\left(n^{*}\right)}=y_{1}$ and that $c_{2}^{\left(n^{*}\right)}$ must satisfy

$$
u^{\prime}\left(y_{1}\right) \geqslant u^{\prime}\left(c_{2}^{\left(n^{*}\right)}\right)>\beta R u^{\prime}\left(y_{1}\right) .
$$

Existence of an equilibrium step number $n^{*}$ is guaranteed through the general existence proof, under Condition 1. It is also evident that $n^{*}=2$ (with associated $c_{2}^{(2)}=y_{2}$ ) is the unique equilibrium step number if and only if $R<\left(u^{\prime}\left(y_{2}\right)\right) /\left(\beta u^{\prime}\left(y_{1}\right)\right)$, which confirms our results in Section 3.3. Finally, the next proposition shows that $n^{*}$ is always unique.

Proposition 16. Suppose $R \geqslant\left(u^{\prime}\left(y_{2}\right)\right) /\left(\beta u^{\prime}\left(y_{1}\right)\right)$. Then the optimal number of steps $n^{*} \geqslant 3$ satisfying (77) is unique.

Proof. The assumption in the proposition rules out autarky $n^{*}=2$ as optimal. Now we prove uniqueness. Let $n^{*} \geqslant 3$ satisfy (77). Take arbitrary $\tilde{n} \neq n^{*}$. First suppose $\tilde{n}<n^{*}$, so that $\tilde{n}=n^{*}-k$ for some $k \geqslant 1$. But then, using the fact that $c_{n^{*}}^{\left(n^{*}\right)} \leqslant c_{\tilde{n}}^{(\tilde{n})}$

$$
\begin{aligned}
u^{\prime}\left(c_{2}^{(\tilde{n})}\right) & =(\beta R)^{-(\tilde{n}-2)} u^{\prime}\left(c_{\tilde{n}}^{(\tilde{n})}\right) \leqslant(\beta R)^{-\left(n^{*}-2\right)+k} u^{\prime}\left(c_{n^{*}}^{\left(n^{*}\right)}\right) \\
& =(\beta R)^{k} u^{\prime}\left(c_{2}^{\left(n^{*}\right)}\right) \leqslant(\beta R)^{k} u^{\prime}\left(y_{1}\right) \leqslant(\beta R) u^{\prime}\left(y_{1}\right),
\end{aligned}
$$


which violates the second inequality of (77) for $n=\tilde{n}$. If one supposes $\tilde{n}>n^{*}$, a similar argument shows that the first inequality of (77) is violated for $n=\tilde{n}$.

Conditional on an optimal step number $n$ it is also straightforward to calculate the stationary distribution.

Proposition 17. Assume $v(y) \equiv 0, y \in Y$. Suppose, income can take two values and is iid, with $\pi=P\left(y=y_{1}\right)$. The stationary distribution is given by atoms at $w_{i}$ with weights $\lambda_{i}$ given by

$$
\begin{aligned}
& \lambda_{1}=\pi^{n-1}, \\
& \lambda_{j}=\pi^{n-j}(1-\pi) \quad \text { for } j=2, \ldots, n
\end{aligned}
$$

where $n$ is the optimal number of steps analyzed above.

Proof. This follows from noting the following. Given any current promise $w_{j}$, the probability for reaching $w_{n}$ in the next period is $1-\pi$. Thus,

$$
\lambda_{n}=(1-\pi) \sum_{j=1}^{n} \lambda_{j}=1-\pi .
$$

Next, for $1<j<n, w_{j}$ can be reached only from $w_{j+1}$ and income $y_{1}$. Thus, $\lambda_{j}=\pi \lambda_{j+1}$. Finally, for $j=1, w_{1}$ can be reached from both $w_{1}$ or from $w_{2}$, provided income is $y_{1}$. Thus, $\lambda_{1}=\pi\left(\lambda_{1}+\lambda_{2}\right)$. Solving these equations for $\lambda_{j}, j=1, \ldots, n-1$ gives the result.

Note that the dynamics of the consumption contract characterized above is similar to that in a standard endogenous incomplete markets model with exogenous outside option (see Krueger and Perri, 1999, who also consider the case $\beta R<1$ ). The qualitative difference that endogenizing the outside option by competition makes is the pre-payment nature of insurance, and thus the fact that low-income agents initially cannot obtain insurance at all. After pre-payment the contract unfolds qualitatively similar to Krueger and Perri (1999), although, quantitatively, less insurance can be achieved in our model as the constraints on the contract are more stringent with the endogenous outside option.

\subsection{Equivalence results}

\subsubsection{A consumption-savings reformulation}

The competitive equilibrium with risk sharing contracts between principals and agents can also be implemented by letting the agent trade in state-contingent one-period Arrow securities, subject to carefully chosen short-sale constraints.

More precisely, consider the consumption-savings problem

$$
\begin{aligned}
& W(y, b)=\max _{c,\left(b\left(y^{\prime}\right)\right)_{y^{\prime} \in Y}}\left\{(1-\beta) u(c)+\beta \sum_{y^{\prime}} \pi\left(y^{\prime} \mid y\right) W\left(y^{\prime}, b\left(y^{\prime}\right)\right)\right\} \\
& \text { s.t. } c+\frac{1}{R} \sum_{y^{\prime} \in Y} \pi\left(y^{\prime} \mid y\right) b\left(y^{\prime}\right)=y+b, \\
& b\left(y^{\prime}\right) \geqslant \underline{b}\left(y^{\prime}\right) \quad \text { for all } y^{\prime} \in Y,
\end{aligned}
$$


where $\underline{b}\left(y^{\prime}\right)$ is a collection of state-contingent borrowing constraints. If $\underline{b}\left(y^{\prime}\right)=0$ for all $y^{\prime} \in Y$, then the agent is prevented from borrowing altogether.

The price of an Arrow security paying one unit of consumption tomorrow, conditional on income realization $y^{\prime}$ is given by $q\left(y^{\prime} \mid y\right)=\left(\pi\left(y^{\prime} \mid y\right) / R\right) b\left(y^{\prime}\right)$. We now want to relate the solution of this consumption-savings problem to the competitive risk sharing contracts equilibrium studied above. Note that the consumption-savings problem treats the interest rate $R$ and the borrowing constraints $\underline{b}\left(y^{\prime}\right)$ as exogenous.

Proposition 18. Any contract equilibrium $V(y, w), w^{\prime}\left(y, w ; y^{\prime}\right), c(y, w)$ and $\left\{U^{\text {Out }}(y)\right\}_{y \in Y}$ can be implemented as a solution $W(y, b), b^{\prime}\left(y, b ; y^{\prime}\right), C(y, b)$ to the consumption-savings problem above with borrowing constraint given by

$$
\underline{b}(y)=\frac{R}{R-1}\left(V\left(y, U^{\mathrm{Out}}(y)-v(y)\right)-a(y)\right) .
$$

Conversely, for given borrowing constraints $\underline{b}(y) \leqslant 0$ and solution to the consumption-savings problem $W(y, b), b^{\prime}\left(y, b ; y^{\prime}\right), C(y, b)$ there exist moving costs

$$
v(y)=W(y, 0)-W(y, \underline{b}(y)) \geqslant 0
$$

such that the solution to the consumption-savings problem can be implemented as a contract equilibrium $V(y, w), w^{\prime}\left(y, w ; y^{\prime}\right), c(y, w)$ and $\left\{U^{\text {Out }}(y)\right\}_{y \in Y}$. The moving costs satisfy

$$
U^{\text {Out }}(y)-v(y)=W(y, \underline{b}(y)) \text { for all } y \in Y .
$$

Proof. The details of the proof are again relegated to the technical appendix; the main logic follows standard duality theory. In the contract economy the state variables of a contract are $(y, w)$, in the consumption-savings problem they are $(y, b)$. Define the mapping between state variables as

$$
\begin{aligned}
b(y, w) & =\frac{R}{R-1}(V(y, w)-a(y)), \\
w(y, b) & =W(y, b),
\end{aligned}
$$

where both functions are strictly increasing in their second arguments and thus invertible. With this mapping it is easy to see that the objective function of the contract problem implies the budget constraint of the consumption problem and the promise keeping constraint implies that the Bellman equation of consumption problem is satisfied. Reversely, the objective of the consumption problem implies the promise keeping constraint and the resource constraint implies the Bellman equation in the contract problem.

The nontrivial parts of the proof shown in the appendix are that any feasible contract satisfies the borrowing constraint in the consumption problem and that any feasible consumption allocation satisfies the utility constraints in the contract problem. It is finally shown by straightforward construction that the contract allocation is optimal (and not just feasible) in the consumption problem. If there exist a superior consumption allocation it is feasible in the contract problem and yields lower costs, a contradiction. The reverse logic shows that the consumption allocation solves the cost minimization problem in the contract minimization problem.

The proposition shows that the contracting problem and the consumption problem are dual to each other. Furthermore, the proposition connects two strands of the previous 
literature. Via our equivalence result, all our findings from the contract economy carry over immediately to Bewley (1986)-type economies with trade in state-contingent Arrow securities subject to short-sale constraints. The borrowing constraints $\underline{b}(y)$ implied by our optimal risk sharing contracts are reminiscent of Alvarez and Jermann's (2000) borrowing constraints that are "not too tight". The proposition shows that, as for their borrowing constraints, agents can be allowed to borrow up to the point at which they are, state by state, indifferent between repaying their debt or defaulting. Instead of suffering financial autarky, as in Alvarez and Jermann (2000), the consequences of default in our model amount to having to hook up with a competitor (and bear the utility cost $v(y)$, if any, from doing so). Thus, one may interpret a solution to our consumption-savings problem as an equilibrium with solvency constraints in the spirit of Alvarez and Jermann. We have as immediate:

Corollary 19. A contract equilibrium with zero moving costs, $v(y)=0$, can be implemented as a solution to the consumption problem with a short-sale constraint, $\underline{b}(y)=0$. Reversely, $a$ solution to the consumption-savings problem prohibiting borrowing can be implemented as a contract equilibrium with $v(y)=0$.

This corollary provides a link to Bulow and Rogoff (1989): if there are no moving costs for agents between intermediaries (such as direct trade sanctions), then competition among intermediaries rules out international debt. The equivalence result also shows that in the contract economy without moving costs at no point in the contract does the "balance" of the agent with the financial intermediary become negative: after the initial payment of the agent the principal owes the agent more future consumption (in an expected discounted value sense) than he receives in expected discounted income from that agent, at each point and contingency in the contract. This, again, highlights the necessary pre-payment feature of the optimal risk sharing contracts derived in this paper.

\subsubsection{Contracts without incentives to renegotiate}

A further interpretation of our environment is one with a single principal and agent in which contracts signed between the principal and the agent have to be such that the agent has no incentive to call for a renegotiation. ${ }^{24}$ The agent is assumed to have all bargaining power in the renegotiation, can demand renegotiation at any point of time, but experiences a disutility $v(y)$ "up-front" from opening the renegotiation. This is equivalent to resetting the promise level $w$ at the beginning of any period. With his bargaining power the agent presses the principal to the point of indifference, i.e. given current income $y$, she will demand a level of utility satisfying

$$
V(y, w)=a(y)
$$

i.e. $w=U^{\text {Out }}(y)$. The contract is thus constrained by $w^{\prime}\left(y, w ; y^{\prime}\right) \geqslant U^{\text {Out }}(y)-v(y)$. The equivalence between contracts in which the agent has no incentive to ever demand renegotiation, and our environment then follows.

\section{Conclusion}

In this paper we constructed a model of long-term relationships between risk averse agents with random income shocks and risk-neutral profit-maximizing principals. We have

\footnotetext{
${ }^{24}$ We decided not to call these contracts renegotiation proof contracts because that term has a different, welldefined meaning in game theory.
} 
assumed one-sided commitment in that only the principal can commit a priori to the longterm contract. The outside option for the agent is given by the best contract offered by competing principals.

We showed that nonnegative steady state cash flow for the principal necessarily imply that the equilibrium implements the autarky solution with no risk sharing in that case. These autarky equilibria can arise if the principal faces sufficiently low interest rates (is sufficiently patient). Otherwise, with sufficiently high interest rates, risk sharing will be observed: this includes in particular the benchmark case of equal discount rates for agents and principals. Agents signing up with the principal will initially pay some "contract fee" in high income states. The principal in turn promises to provide costly insurance later on in the life of the contract. The contract fee thus acts as a commitment device for the agent which turns into a liability for the (committed) principal later on.

\section{Appendix A. The sequential formulation of the game between locations}

To formulate the game sequentially, we need some more notation. For dates $q$ and $t \geqslant q$, let $y_{i}^{t, q}=\left(y_{q, i}, y_{q+1, i}, \ldots, y_{t, i}\right)$ denote the endowment history from $q$ to $t$ for agent $i$. A contract for agents newly arriving at principal $j$ at date $q$ specifies mappings $c_{t ; q, j}\left(y_{i}^{t, q}\right), t=q, q+1, \ldots$, defining consumption given the location-specific endowment history from date $q$ to date $t$. We assume that agents never return to a location they left, so that there is no issue of "resurrecting" old records. Agents originally present at principal $j$ are assumed to draw their initial income $y_{0, i}$ from some initial distribution. For the recursive formulation, we shall assume that this initial distribution is the stationary distribution.

Principals behave competitively and agents arrive with a "blank" history, i.e. a new principal does not make particular use of the fact that new arrivals must be agents who have defaulted on their previous principal. As mentioned above, to make this assumption more appealing, one could assume that a fraction $\varepsilon$ of agents is forced to move every period anyhow: in equilibrium, these are the only movers, so it is reasonable for the principal in the new location not to attach any particular significance to the fact that an agent has switched locations. The game unfolds as follows:

1. A new date $t$ begins and each agent draws his new endowment $y_{t, i}$.

2. Each principal $j \in[0 ; 1]$ issues a new contract $c_{s ; q, j}\left(y_{i}^{s, t}\right), s=t, t+1, \ldots$ for agents willing sign with him this period.

3. Each agent decides whether to move or not, choosing the new principal $j$ according to his or her preferences. He (or she) keeps the endowment process $y$ including the current endowment $y_{t, i}$.

4. Given the current principal $j$, arrival date $q \leqslant t$ in that location and current endowment history $y^{t, q}$, agents provide their income to the principal and receive consumption goods $c_{t ; q, j}\left(y_{i}^{t, q}\right), t=q, q+1, \ldots$

5. Let $\mu_{j, t}$ denote the measure of agents at principal $j$ at date $t$ (after the moving decision). The principal receives the total resource surplus

$$
S_{j, t}=\int\left(y_{t, i}-c_{t, i}\right) \mu_{j, t}(\mathrm{~d} i)
$$


We allow $S_{j, t}$ to be negative. The objective of the principals is to maximize

$$
U_{j}^{(P)}=\left(1-\frac{1}{R}\right) E_{0}\left[\sum_{t=0}^{\infty} R^{-t} S_{j, t}\right] .
$$

We focus on stationary symmetric sub-game perfect equilibria, giving rise to the recursive formulation in the main body of the paper.

\section{References}

Abreu, D., Pearce, D., Stacchetti, E., 1986. Optimal cartel equilibria with imperfect monitoring. Journal of Economic Theory 39, 251-269.

Alvarez, F., Jermann, U., 2000. Efficiency, equilibrium and asset pricing with risk of default. Econometrica 68, $775-797$.

Alvarez, F., Jermann, U., 2001. Quantitative asset pricing implications of endogenous solvency constraints. Review of Financial Studies 14, 1117-1152.

Atkeson, A., 1991. International lending with moral hazard and risk of repudiation. Econometrica 59, $1069-1089$.

Atkeson, A., Lucas, R., 1992. On efficient distribution with private information. Review of Economic Studies 59, $427-453$.

Atkeson, A., Lucas, R., 1995. Efficiency and equality in a simple model of efficient unemployment insurance. Journal of Economic Theory 66, 64-88.

Beaudry, P., DiNardo, J., 1991. The effect of implicit contracts on the movement of wages over the business cycle: evidence from micro data. Journal of Political Economy 99, 665-688.

Bewley, T., 1986. Stationary monetary equilibrium with a continuum of independently fluctuating consumers. In: Hildenbrand, W., Mas-Colell, A. (Eds.), Contributions to Mathematical Economics in Honor of Gerard Debreu. North-Holland, Amsterdam.

Bulow, J., Rogoff, K., 1989. Sovereign debt: is to forgive to forget? American Economic Review 79, 43-50.

Fudenberg, D., Holmstrom, B., Milgrom, P., 1990. Short-term contracts and long-term agency relationships. Journal of Economic Theory 51, 1-31.

Ghosh, P., Ray, D., 1996. Cooperation in community interaction without information flows. Review of Economic Studies 63, 491-519.

Green, E., 1987. Lending and smoothing of uninsurable income. In: Prescott, E., Wallace, N. (Eds.), Contractual Arrangements for Intertemporal Trade. University of Minnesota Press, Minneapolis.

Harris, M., Holmstrom, B., 1982. A theory of wage dynamics. Review of Economic Studies 49, 315-333.

Kocherlakota, N., 1996. Implications of efficient risk sharing without commitment. Review of Economic Studies 63, 595-609.

Kehoe, T., Levine, D., 1993. Debt constrained asset markets. Review of Economic Studies 60, 865-888.

Kehoe, T., Levine, D., 2001. Liquidity constrained markets versus debt constrained markets. Econometrica 69 , 575-598.

Kletzer, K., Wright, B., 2000. Sovereign debt as intertemporal barter. American Economic Review 90, 621-639.

Krueger, D., 1999. Risk sharing with incomplete markets: macroeconomic and fiscal policy implications. Ph.D. Thesis, University of Minnesota.

Krueger, D., Perri, F., 1999. Risk sharing: private insurance markets or redistributive taxes. Federal Reserve Bank of Minneapolis Staff Report 262.

Ligon, E., Thomas, J., Worrall, T., 2000. Mutual insurance, individual savings, and limited commitment. Review of Economic Dynamics 3, 216-246.

Lustig, H., 2001. Bankruptcy and asset prices. Mimeo, UCLA.

Malcomson, J., 1999. Individual employment contracts. In: Ashenfelter, O., Card, D. (Eds.), Handbook of Labor Economics, vol. 3B. Elsevier Science, North-Holland Amsterdam, pp. 2291-2372.

Malcomson, J., Spinnewyn, F., 1988. The multiperiod principal-agent problem. Review of Economic Studies 55, 391-407.

Phelan, C., 1994. Incentives and aggregate shocks. Review of Economic Studies 61, 681-700.

Phelan, C., 1995. Repeated moral hazard and one-sided commitment. Journal of Economic Theory 66, 488-506. 
Ray, D., 2002. The time structure of self-enforcing agreements. Econometrica 70, 547-582.

Rey, P., Salanie, B., 1990. Long-term, short-term and renegotiation: on the value of commitment in contracting. Econometrica 58, 597-619.

Rey, P., Salanie, B., 1996. On the value of commitment with asymmetric information. Econometrica 64, 1395-1414.

Spear, S., Srivastava, S., 1987. On repeated moral hazard with discounting. Review of Economic Studies 54, 599-617.

Stokey, N., Lucas, R., Prescott, E., 1989. Recursive Methods in Economic Dynamics. Harvard University Press, Cambridge, MA.

Thomas, J., Worrall, T., 1988. Self-enforcing wage contracts. Review of Economic Studies 55, 541-554. 